NASA/TM-1998-206565

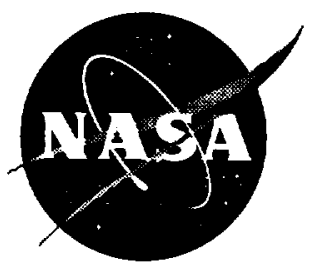

\title{
Flight Stability and Control and Performance Results from the Linear Aerospike SR-71 Experiment (LASRE)
}

Timothy R. Moes, Brent R. Cobleigh, Timothy H. Cox, Timothy R. Conners, and Kenneth W. Iliff

Dryden Flight Research Center

Edwards, California

Bruce G. Powers

Analytical Services and Materials, Inc.

Edwards, California

National Aeronautics and

Space Administration

Dryden Flight Research Center

Edwards, California 93523-0273 


\section{NOTICE}

Use of trade names or names of manufacturers in this document does not constitute an official endorsement of such products or manufacturers, either expressed or implied, by the National Aeronautics and Space Administration.

Available from the following:

NASA Center for AeroSpace Information (CASI) 7121 Standard Drive

Hanover, MD 21076-1320

(301) 621-0390
National Technical Information Service (NTIS) 5285 Port Royal Road Springfield, VA 22161-2171

(703) $487-4650$ 


\title{
FLIGHT STABILITY AND CONTROL AND PERFORMANCE RESULTS FROM THE LINEAR AEROSPIKE SR-71 EXPERIMENT (LASRE)
}

\author{
Timothy R. Moes," Brent R. Cobleigh, ${ }^{*}$ Timothy H. Cox, ${ }^{\dagger}$ \\ Timothy R. Conners, ${ }^{*}$ and Kenneth W. Iliff* \\ NASA Dryden Flight Research Center, \\ Edwards, CA \\ Bruce G. Powers ${ }^{\dagger}$ \\ Analytical Services and Materials, Inc. \\ Edwards, CA
}

\begin{abstract}
$\underline{\text { Abstract }}$
The Linear Aerospike SR-71 Experiment (LASRE) is presently being conducted to test a 20-percent-scale version of the Linear Aerospike rocket engine. This rocket engine has been chosen to power the X-33 Single Stage to Orbit Technology Demonstrator Vehicle. The rocket engine was integrated into a lifting body configuration and mounted to the upper surface of an SR-71 aircraft. This paper presents stability and control results and performance results from the envelope expansion flight tests of the LASRE configuration up to Mach 1.8 and compares the results with wind tunnel predictions. Longitudinal stability and elevator control effectiveness were well-predicted from wind tunnel tests. Zero-lift pitching moment was mispredicted transonically. Directional stability, dihedral stability, and rudder effectiveness were overpredicted. The SR-71 handling qualities were never significantly impacted as a result of the missed predictions. Performance results confirmed the large amount of wind-tunnel-predicted transonic drag for the LASRE configuration. This drag increase made the performance of the vehicle so poor that acceleration through transonic Mach numbers could not be achieved on a hot day without depleting the available fuel.
\end{abstract}

\section{Nomenclature}

$a_{x} \quad$ longitudinal accelerometer output (positive forward), $\mathrm{ft} / \mathrm{sec}^{2}$

*Aerospace Engineer, AIAA member.

${ }^{\dagger}$ Aerospace Engineer.

Copyright $(\odot 1998$ by the American Institute of Aeronautics and Astronautics, Inc. No copyright is asserted in the United States under Title 17, U.S. Code. The U.S. Government has a royalty-free license to exercise all rights under the copyright claimed herein for Governmental purposes. All other rights are reserved by the copyright owner.

\begin{tabular}{|c|c|}
\hline$a_{y}$ & $\begin{array}{l}\text { lateral accelerometer output (positive } \\
\text { toward the right), } \mathrm{ft} / \mathrm{sec}^{2}\end{array}$ \\
\hline$a_{z}$ & $\begin{array}{l}\text { vertical accelerometer output (positive } \\
\text { down), ft/sec }\end{array}$ \\
\hline$b$ & SR-71 reference span, $56.7 \mathrm{ft}$ \\
\hline B.L. & butt line, in. \\
\hline$c$ & SR-71 mean aerodynamic chord, $37.7 \mathrm{ft}$ \\
\hline c.g. & center of gravity, percent $c$ \\
\hline$C_{l}$ & rolling moment coefficient \\
\hline$C_{l_{b}}$ & $\begin{array}{l}\text { rolling moment bias, coefficient estimate } \\
\text { for } \beta=0^{\circ}\end{array}$ \\
\hline$C_{l_{p}}$ & $\begin{array}{l}\text { rolling moment due to nondimensional roll } \\
\text { rate derivative, } \partial C_{l} / \partial(p b / 2 V), \mathrm{rad}^{-1}\end{array}$ \\
\hline$C_{l_{r}}$ & $\begin{array}{l}\text { rolling moment due to nondimensional yaw } \\
\text { rate derivative, } \partial C_{l} / \partial(\mathrm{rb} / 2 \mathrm{~V}), \mathrm{rad}^{-1}\end{array}$ \\
\hline$C_{l_{\beta}}$ & $\begin{array}{l}\text { rolling moment due to angle of sideslip } \\
\text { derivative, } \partial C_{l} / \partial \beta, \mathrm{deg}^{-1}\end{array}$ \\
\hline$C_{l_{\delta a}}$ & $\begin{array}{l}\text { rolling moment due to aileron derivative, } \\
\partial C_{l} / \partial \delta a, \mathrm{deg}^{-1}\end{array}$ \\
\hline$C_{l_{\delta r}}$ & $\begin{array}{l}\text { rolling moment due to rudder derivative, } \\
\partial C_{l} / \partial \delta r, \mathrm{deg}^{-1}\end{array}$ \\
\hline$C_{m}$ & pitching moment coefficient \\
\hline$C_{m_{b}}$ & $\begin{array}{l}\text { pitching moment bias, linear coefficient } \\
\text { estimate for } \alpha=0^{\circ}\end{array}$ \\
\hline$C_{m_{q}}$ & $\begin{array}{l}\text { pitching moment due to nondimensional } \\
\text { pitch rate derivative, } \partial C_{m} / \partial(q c / 2 V) \text {, } \\
\text { rad }^{-1}\end{array}$ \\
\hline$C_{m_{\alpha}}$ & $\begin{array}{l}\text { pitching moment due to angle of attack } \\
\text { derivative, } \partial C_{m} / \partial \alpha, \mathrm{deg}^{-1}\end{array}$ \\
\hline$C_{m_{\delta e}}$ & $\begin{array}{l}\text { pitching moment due to elevon derivative, } \\
\partial C_{m} / \partial \delta e, \mathrm{deg}^{-1}\end{array}$ \\
\hline
\end{tabular}




\begin{tabular}{|c|c|c|c|}
\hline$C_{n}$ & yawing moment coefficient & $g$ & acceleration of gravity, $32.174 \mathrm{ft} / \mathrm{sec}^{2}$ \\
\hline \multirow[t]{2}{*}{$C_{n_{b}}$} & \multirow{2}{*}{$\begin{array}{l}\text { yawing moment bias, coefficient estimate } \\
\text { for } \beta=0^{\circ}\end{array}$} & $H p$ & pressure altitude, $\mathrm{ft}$ \\
\hline & & $I_{x}$ & roll moment of inertia, slug- $\mathrm{ft}^{2}$ \\
\hline \multirow[t]{2}{*}{$C_{n_{p}}$} & \multirow{2}{*}{$\begin{array}{l}\text { yawing moment due to nondimensional } \\
\text { roll rate derivative, } \partial C_{n} / \partial(p b / 2 V) \\
\text { rad }^{-1}\end{array}$} & $I_{x z}$ & cross product of inertia, slug- $\mathrm{ft}^{2}$ \\
\hline & & $I_{y}$ & pitch moment of inertia, slug- $\mathrm{ft}^{2}$ \\
\hline \multirow{2}{*}{$C_{n_{r}}$} & \multirow{2}{*}{$\begin{array}{l}\text { yawing moment due to nondimensional } \\
\text { yaw rate derivative, } \partial C_{n} / \partial(r b / 2 V) \text {, } \\
\text { rad }^{-1}\end{array}$} & $I_{z}$ & yaw moment of inertia, slug- $\mathrm{ft}^{2}$ \\
\hline & & KEAS & equivalent airspeed, knots \\
\hline \multirow[t]{2}{*}{$C_{n_{\beta}}$} & \multirow{2}{*}{$\begin{array}{l}\text { yawing moment due to angle of sideslip } \\
\text { derivative, } \partial C_{n} / \partial \beta, \mathrm{deg}^{-1}\end{array}$} & & linear aerospike SR-71 experiment \\
\hline & & $m$ & mass, slugs \\
\hline \multirow[t]{2}{*}{$C_{n_{\delta a}}$} & \multirow{2}{*}{$\begin{array}{l}\text { yawing moment due to aileron derivative, } \\
\partial C_{n} / \partial \delta a, \mathrm{deg}^{-1}\end{array}$} & $p$ & $\mathrm{roll} \mathrm{rate}, \mathrm{rad} / \mathrm{sec}$ \\
\hline & & $\dot{p}$ & roll acceleration, $\mathrm{rad} / \mathrm{sec}^{2}$ \\
\hline$C_{n_{\delta r}}$ & \multirow{2}{*}{$\begin{array}{l}\text { yawing moment due to rudder derivative, } \\
\partial C_{n} / \partial \delta r, \mathrm{deg}^{-1}\end{array}$} & $q$ & pitch rate, $\mathrm{rad} / \mathrm{sec}$ \\
\hline$C_{N}$ & & $\bar{q}$ & dynamic pressure, $\mathrm{lb} / \mathrm{ft}^{2}$ \\
\hline \multirow[t]{2}{*}{$C_{N_{b}}$} & normal force coefficient & $\dot{q}$ & pitch acceleration, $\mathrm{rad} / \mathrm{sec}^{2}$ \\
\hline & $\begin{array}{l}\text { normal force bias, linear coefficient } \\
\text { estimate for } \alpha=0^{\circ}\end{array}$ & $r$ & yaw rate, $\mathrm{rad} / \mathrm{sec}$ \\
\hline \multirow{2}{*}{$C_{N_{q}}$} & \multirow{2}{*}{$\begin{array}{l}\text { normal force due to nondimensional pitch } \\
\text { rate derivative, } \partial C_{N} / \partial(q c / 2 V), \text { rad }^{-1}\end{array}$} & $\dot{r}$ & yaw acceleration, $\mathrm{rad} / \mathrm{sec}^{2}$ \\
\hline & & ref & aerodynamic moment derivatives correct \\
\hline$C_{N_{\alpha}}$ & $\begin{array}{l}\text { normal force due to angle of attack } \\
\text { derivative, } \partial C_{N} / \partial \alpha, \mathrm{deg}^{-1}\end{array}$ & & $\begin{array}{l}\text { to the } 25 \text { percent } c \text { moment reference } \\
\text { (F.S. } 900 \text { ) }\end{array}$ \\
\hline \multirow[t]{2}{*}{$C_{N_{\delta e}}$} & \multirow{2}{*}{$\begin{array}{l}\text { normal force due to elevon derivative, } \\
\partial C_{N} / \partial \delta e, \text { deg }^{-1}\end{array}$} & $S$ & SR-71 reference area, $1605 \mathrm{ft}^{2}$ \\
\hline & & $T$ & thrust, lb \\
\hline$C_{Y}$ & side force coefficient & $u$ & body $\mathrm{x}$-axis wind-relative velocity, $\mathrm{f} / \mathrm{sec}$ \\
\hline$C_{Y_{b}}$ & $\begin{array}{l}\text { side force bias, coefficient estimate for } \\
\qquad \beta=0^{\circ}\end{array}$ & $\dot{u}$ & $\begin{array}{l}\text { body } x \text {-axis wind-relative acceleration, } \\
\mathrm{ft} / \mathrm{sec}^{2}\end{array}$ \\
\hline$C_{Y_{p}}$ & $\begin{array}{l}\text { side force due to nondimensional roll rate } \\
\text { derivative, } \partial C_{Y} / \partial(p b / 2 V), \text { rad }^{-1}\end{array}$ & $v$ & body $\mathrm{y}$-axis wind-relative velocity, $\mathrm{ft} / \mathrm{sec}$ \\
\hline \multirow[t]{2}{*}{$C_{Y_{r}}$} & \multirow{2}{*}{$\begin{array}{l}\text { side force due to nondimensional yaw rate } \\
\text { derivative, } \partial C_{Y} / \partial(r b / 2 V), \text { rad }^{-1}\end{array}$} & $\dot{v}$ & $\begin{array}{l}\text { body y-axis wind-relative acceleration, } \\
\mathrm{ft} / \mathrm{sec}^{2}\end{array}$ \\
\hline & & $V$ & true airspeed, $\mathrm{ft} / \mathrm{sec}$ \\
\hline$C_{Y_{\beta}}$ & $\begin{array}{l}\text { side force due to angle of sideslip } \\
\text { derivative, } \partial C_{Y} / \partial \beta, \text { deg }^{-1}\end{array}$ & $\dot{V}$ & $\begin{array}{l}\text { flightpath wind-relative acceleration, } \\
\mathrm{ft} / \mathrm{sec}^{2}\end{array}$ \\
\hline$C_{Y_{\delta a}}$ & $\begin{array}{l}\text { side force due to aileron derivative, } \\
\partial C_{Y} / \partial \delta a, \operatorname{deg}^{-1}\end{array}$ & $w$ & body $\mathrm{z}$-axis wind-relative velocity, $\mathrm{ft} / \mathrm{sec}$ \\
\hline$C_{Y_{\delta r}}$ & $\begin{array}{l}\text { side force due to rudder } \\
\text { derivative, } \partial C_{Y} / \partial \delta r, \mathrm{deg}^{-1}\end{array}$ & $\dot{w}$ & $\begin{array}{l}\text { body } \mathrm{z} \text {-axis wind-relative acceleration, } \\
\mathrm{ft} / \mathrm{sec}^{2}\end{array}$ \\
\hline$D$ & drag, lbf & $\alpha$ & wing-reference-plane angle of attack, deg \\
\hline EGT & exhaust gas temperature & $\beta$ & angle of sideslip, deg \\
\hline$F_{e}$ & excess thrust, lbf & $\dot{\beta}$ & $\begin{array}{l}\text { time rate of change of angle of sideslip, } \\
\mathrm{rad} / \mathrm{sec}\end{array}$ \\
\hline F.S. & fuselage station, in. & $\delta a$ & aileron deflection, deg \\
\hline
\end{tabular}




$\begin{array}{cl}\delta e & \text { elevon deflection, deg } \\ \delta r & \text { rudder deflection, deg } \\ \theta & \text { pitch angle, deg } \\ \dot{\theta} & \begin{array}{l}\text { time rate of change of pitch attitude, } \\ \mathrm{rad} / \mathrm{sec}\end{array} \\ \phi & \text { roll angle, deg } \\ \dot{\phi} & \text { time rate of change of roll angle, } \mathrm{rad} / \mathrm{sec} \\ & \text { Introduction }\end{array}$

The goal to dramatically reduce the cost of access to space has prompted NASA to fund the development of the X-33 Single Stage to Orbit Technology Demonstrator Vehicle. Lockheed Martin Skunk Works, Palmdale, California, has been chosen to build the $\mathrm{X}-33$, which incorporates a linear aerospike rocket engine (built by Boeing Rocketdyne, Canoga Park, California) into a lifting body configuration. The principle advantage of the aerospike rocket is the inherent altitude compensation provided by the nozzle. This altitude-compensating ability theoretically allows the rocket engine to achieve increased specific impulse performance during the low-altitude portion of a flight as compared with a conventional bell nozzle rocket (fig. 1).

The aerospike rocket was first developed and ground tested in the 1960 's ${ }^{1,2}$, but has never been flight tested. In order to obtain flight data on an aerospike rocket incorporated into a lifting body configuration, a cooperative project between the NASA Dryden Flight Research Center, Edwards, California, and Lockheed Martin was initiated. The project approach was to flight test an aerospike rocket using an SR-71 aircraft as the carrier vehicle in a project known as the Linear Aerospike SR-71 Experiment (LASRE). The primary goal of the project was to gather installed rocket engine performance data at flight conditions approximating the $\mathrm{X}-33$ trajectory.

The LASRE lifting body configuration is roughly a 20-percent scale model of an X-33. The entire test apparatus, known as the LASRE pod, is shown mounted on the SR-71 aircraft in figure 2. The large size of the LASRE pod significantly altered the aerodynamics of the SR-71 configuration and, therefore, the early flights of the program were used to clear the flight envelope before attempts were made to carry volatile propellants and fire the rocket engine. These envelope expansion flights were used to address flutter clearance, stability and control concerns, and to obtain performance data on the LASRE configuration. Many of the concerns that required flight testing were identified during a series of wind tunnel tests conducted prior to fabrication of the LASRE pod $^{3}$. These concerns included such issues as transonic pitch-trim authority and the large drag caused by the pod.

This report presents the aerodynamic data that were gathered during the envelope expansion flights These data include flight measured stability and control data

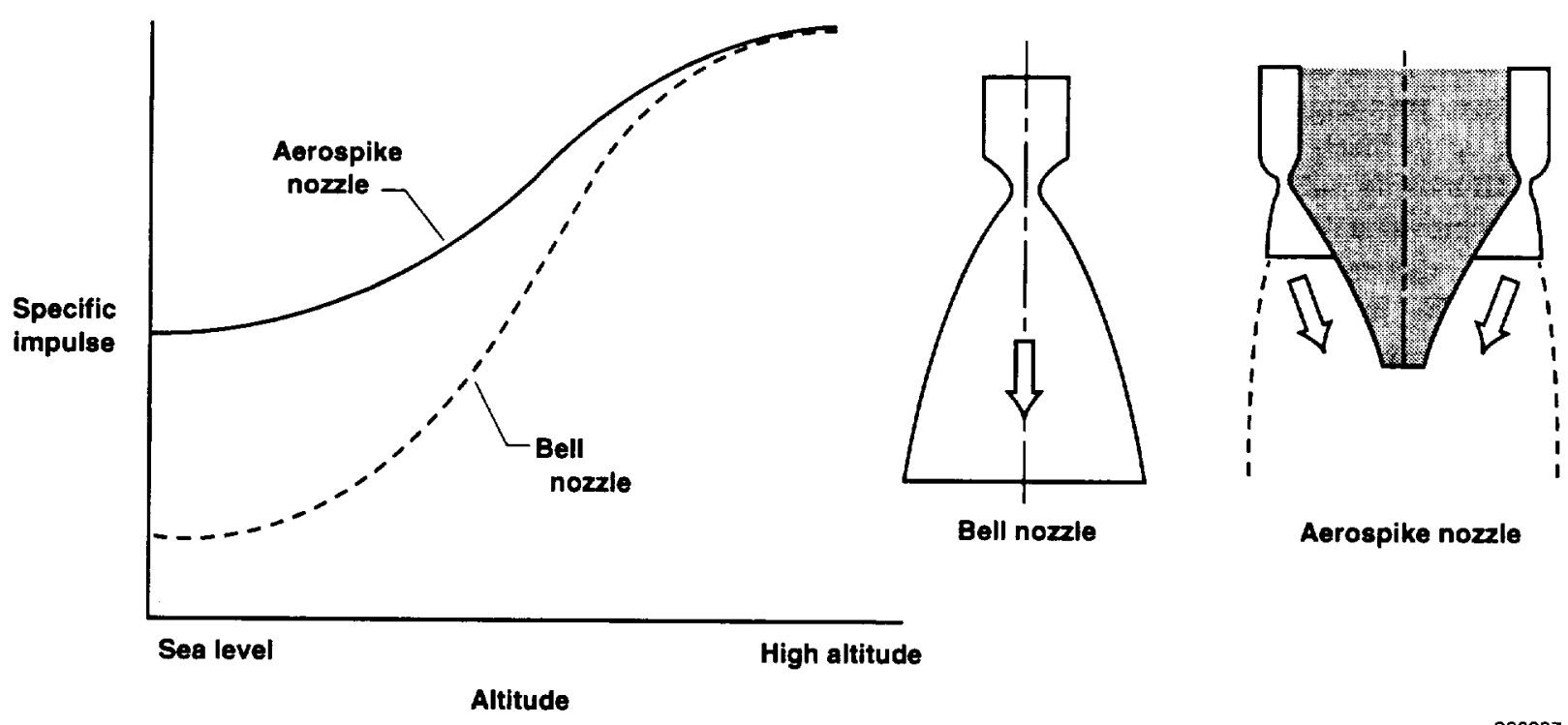

Figure 1. Qualitative comparison of aerospike and bell nozzle specific impulse. 


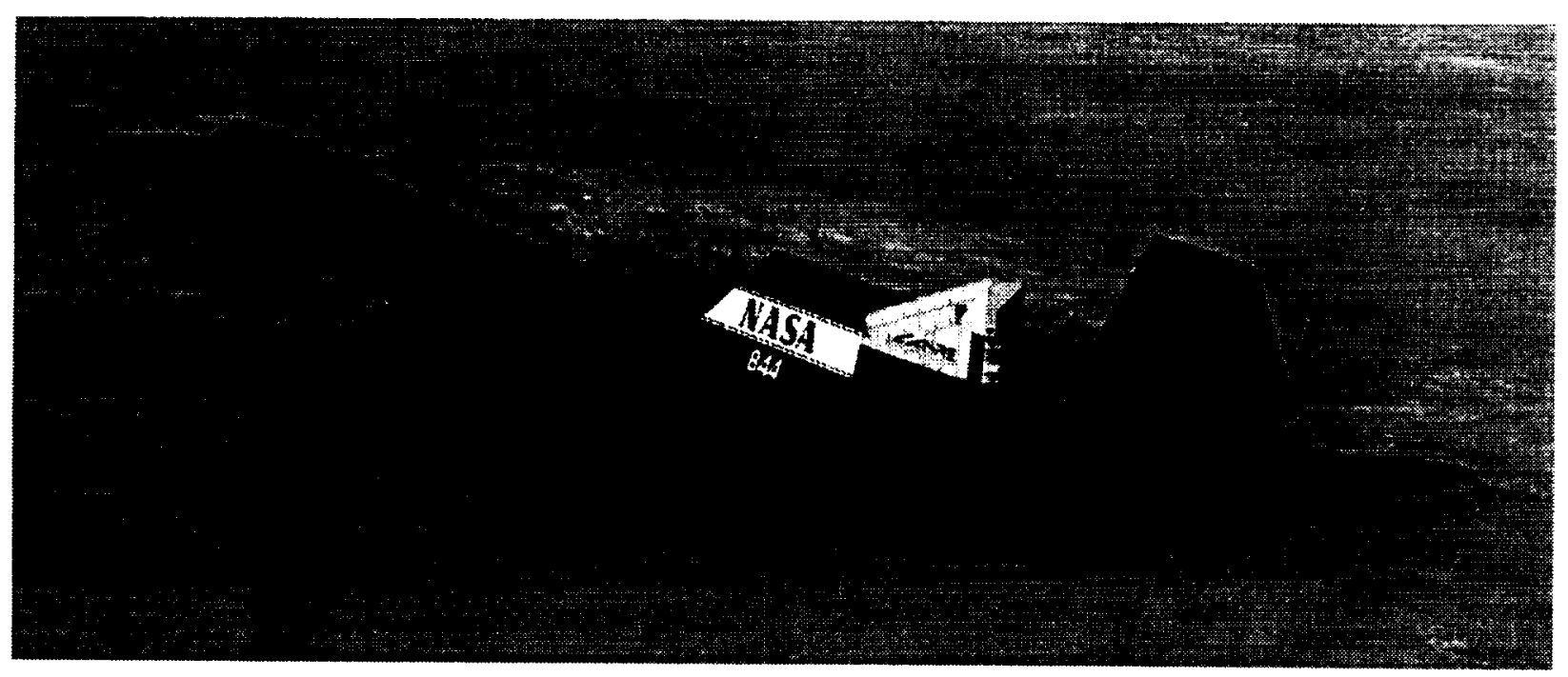

EC97 44295-103

Figure 2. LASRE configuration in flight.

and performance data up to Mach 1.8. The flight data are compared with preflight wind tunnel predictions. The importance of flight simulation to envelope expansion testing is discussed in detail. Use of trade names or names of manufacturers in this document does not constitute an official endorsement of such products or manufacturers, either expressed or implied, by the National Aeronautics and Space Administration.

\section{Configuration Description}

\section{Baseline SR-71 Aircraft}

A Lockheed Martin SR-71A aircraft was used as the carrier vehicle for the LASRE. The SR-71A aircraft is a two-place, twin-engine aircraft capable of cruising at speeds up to Mach 3.2 and altitudes up to $85,000 \mathrm{ft}$. Twin all-moving rudders mounted on top of the engine nacelles provided directional control, while inboard and outboard elevons provided longitudinal and lateral control. The inboard and outboard surfaces moved simultaneously. However, the outboard elevons were rigged with an additional $3^{\circ}$ trailing-edge-up incidence in comparison with the inboard elevons. The control surface actuators were powered using two independent hydraulic fluid systems. Two Pratt \& Whitney J58 turbojet engines were used to power the aircraft.

\section{SR-71 Modifications}

The SR-71 aircraft for the LASRE program included thrust enhancement and structural modifications. It was decided to increase the thrust of the J58 engines based on wind tunnel predictions of significant additional drag resulting from the LASRE pod. The thrust enhancement included trimming the maximum rotor speed and core fuel flow to the top end of their operating bands and uptrimming the turbine exhaust gas temperatures (EGT). The pilot-controlled EGT uptrim was only used during the transonic and low-supersonic acceleration. The aircraft internal structure was extensively modified to support mounting a structure of up to $14,500 \mathrm{lb}$ on the top of the fuselage. ${ }^{4}$

\section{LASRE Pod}

The LASRE components mounted to the top of the SR-71 were referred to as the canoe, kayak, reflection plane, and model (fig. 3). Collectively, these structural components were referred to as the LASRE pod. The canoe was installed on the SR-71 fuselage and was designed to contain the gaseous hydrogen fuel and liquid water needed for cooling. The kayak, located beneath the reflection plane and on top of the canoe, sets the model incidence angle to $2^{\circ}$ nosedown to align the lower part of the model with the local flow over the top of the SR-71 airplane. The reflection plane was mounted on top of the kayak to help promote uniform flow in the region of the model. The model was designed to approximate a half-span lifting body with a $20^{\circ}$ swept-cylinder leading edge and spherical nose. Liquid oxygen and ignitor materials required to operate the rocket engine were stored in the model. The model was mounted vertically so that sideslip of the SR-71 airplane would impart angle of attack on the model. With a full load of expendables the pod weighed approximately 

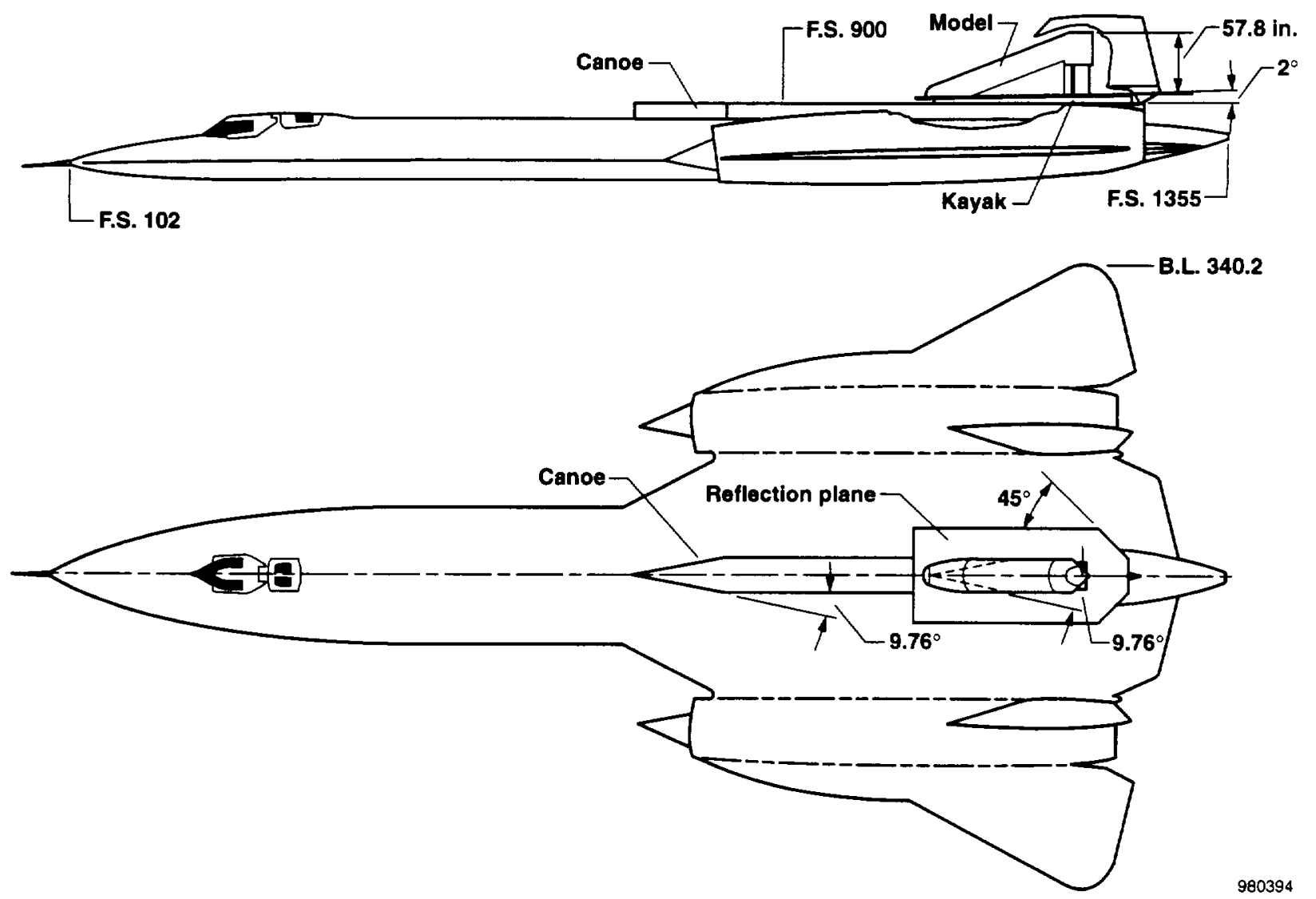

Figure 3. Side and planform views of the LASRE configuration.

$14,140 \mathrm{lb}$. The total empty weight of the LASRE configuration was approximately $74,870 \mathrm{lb}$. Fuel loads of up to $62,000 \mathrm{lb}$ have been used during the flight tests. To compensate for center of gravity (c.g.) shifts caused by the pod weight, $5000 \mathrm{lb}$ of fuel in the forward tank was considered unusable for the flight.

\section{Instrumentation}

The SR-71 was equipped with a complete set of air data and inertial instrumentation. Free-stream pitotstatic air data were obtained from a calibrated noseboom. Angle of attack $(\alpha)$ and angle of sideslip $(\beta)$ data were obtained from a 4-hole hemispherical probe dog-legged to the noseboom. The angle of attack is referenced to the wing reference plane which is $1.2^{\circ}$ nosedown in incidence compared with the fuselage centerline reference plane. Angle of attack and angle of sideslip measurements were lagged from 0.2 to 0.4 seconds because of the pneumatic plumbing. These lags were accounted for by time skews in the data analysis. Pitch and roll attitude information were obtained from the SR-71 inertial navigation system. Angular rate and linear accelerations were measured using strapdown sensors installed on the SR-71.
Accelerations were corrected to the c.g. using angular rate information from the strapdown sensors. All control surface positions were measured with the exception of the right outboard elevon. The inboard and left outboard elevon actuators were instrumented with hydraulic pressure sensors for the trailing-edge-up deflection. Vehicle weight and c.g. were obtained using fuel tank measurements.

\section{Analysis Methods}

Stability and control and aircraft transonic performance data were of the most interest during the early LASRE test flights. The methods used to analyze these data are now discussed, including the importance of preflight wind tunnel predictions and flight simulation.

\section{Stability and Control}

Stability and control derivatives were obtained from flight data using maximum-likelihood parameter estimation techniques. ${ }^{5,6}$ As is normally the case, longitudinal and lateral-directional analysis were performed separately. 


\section{Longitudinal}

Pitch doublet maneuvers were flown at specified Mach numbers and altitudes to obtain the longitudinal stability and control derivatives. The state equations used in the longitudinal analysis are:

$$
\begin{gathered}
\dot{\alpha}=-\frac{\bar{q} S}{m V} C_{N} \cos \alpha+q-\tan \beta(p \cos \alpha+r \sin \alpha) \\
+\frac{g}{V}(\cos \phi \cos \theta \cos \alpha+\sin \theta \sin \alpha) \\
\dot{q}=\bar{q} S c C_{m}+r p\left(I_{z}-I_{x}\right)+\left(r^{2}-p^{2}\right) I_{x z} \\
\dot{\theta}=q \cos \phi-r \sin \phi
\end{gathered}
$$

The response parameters measured in flight and compared with estimations were angle of attack, pitch rate, pitch attitude, and normal acceleration. Angle of attack and normal acceleration measurements were corrected to the c.g. Normal acceleration was weighted heavier in the analysis than angle of attack because the angle of attack calibration was suspect. The force and moment coefficients were expanded using the linear approximation:

$$
\begin{aligned}
& C_{N}=C_{N_{b}}+C_{N_{\alpha}} \alpha+\frac{c}{2 V} C_{N_{q}} q+C_{N_{\delta_{e}}} \delta e \\
& C_{m}=C_{m_{b}}+C_{m_{\alpha}} \alpha+\frac{c}{2 V} C_{m_{q}} q+C_{m_{\delta e}} \delta e
\end{aligned}
$$

The coefficients are based on a reference area of $1605 \mathrm{ft}^{2}$ and a mean aerodynamic chord, $c$, of $37.7 \mathrm{ft}$. The moment reference is at 25 percent $c$, which is at fuselage station (F.S.) 900 . The coefficient with the subscript $b$ is a linear extrapolation from the coefficient at the average angle of attack of the maneuver to zero angle of attack. ${ }^{5}$ Axial force coefficients were not used in this analysis because the axial force derivatives were not expected to affect flying qualities and because it is generally difficult to get good identifiability of these derivatives. Axial loads, however, were of importance to the performance analysis and are discussed later. All of the longitudinal derivatives in equations 4 and 5 were estimated in the analysis. Only $C_{m_{\alpha}}$ and $C_{m_{\delta e}}$ results are presented in this report because these are of crucial interest to the configuration stability and control.

\section{Lateral-Directional}

Yaw and roll doublet maneuvers were flown at specified Mach numbers and altitudes to obtain the lateral-directional stability and control derivatives. The state equations used in the lateral-directional analysis are:

$$
\begin{gathered}
\dot{\beta}=\frac{\bar{q} S}{m V} C_{Y}+p \sin \alpha-r \cos \alpha+\frac{g}{V} \sin \phi \cos \theta \\
\dot{p} I_{x}-\dot{r} I_{x z}=\bar{q} S b C_{l}+q r\left(I_{y}-I_{z}\right)+p q I_{x z} \\
\dot{r} I_{z}-\dot{p} I_{x z}=\bar{q} S b C_{n}+p q\left(I_{x}-I_{y}\right)-q r I_{x z} \\
\dot{\phi}=p+q \tan \theta \sin \phi+r \tan \theta \cos \phi
\end{gathered}
$$

The reference span, $b$, was $56.7 \mathrm{ft}$. The response parameters measured and estimated were angle of sideslip, roll rate, yaw rate, bank angle, and lateral acceleration. Angle of sideslip and lateral acceleration measurements were corrected to the c.g. Because the angle of sideslip calibration was suspect, lateral acceleration was weighted heavier in the analysis than angle of sideslip. The force and moment coefficient equations are:

$$
\begin{aligned}
C_{Y}= & C_{Y_{b}}+C_{Y_{\beta} \beta} \beta+\frac{b}{2 V}\left(C_{Y_{p}} p+C_{Y_{r}} r\right) \\
& +C_{Y_{\delta a}} \delta a+C_{Y_{\delta r}} \delta r \\
C_{l}= & C_{l_{b}}+C_{l_{\beta}} \beta+\frac{b}{2 V}\left(C_{l_{p}} p+C_{\left.l_{r} r\right)}\right. \\
& +C_{l_{\delta a}} \delta a+C_{l_{\delta r}} \delta r \\
C_{n}= & C_{n_{b}}+C_{n_{\beta}} \beta+\frac{b}{2 V}\left(C_{n_{p}} p+C_{n_{r}} r\right) \\
& +C_{n_{\delta a}} \delta a+C_{n_{\delta r}} \delta r
\end{aligned}
$$

The coefficient with the subscript $b$ is the value of the coefficient at zero angle of sideslip. All the lateraldirectional derivatives in equations $10-12$ were estimated in the analysis. Only $C_{n_{\beta}}, C_{l_{\beta}}, C_{n_{\delta r}}$, and $C_{l_{\delta a}}$ results are presented in this report because these are the most relevant to the configuration stability and control.

\section{Performance}

The SR-71's J58 engines were not instrumented for thrust measurements. Consequently, thrust and drag could not be independently identified and an excess thrust performance analysis was used instead. Excess thrust was obtained from flight data and simulator data and then the two were compared. 
Acceleration maneuvers at low angle of attack and near zero angle of sideslip were used to obtain the performance data. Excess thrust, $F_{e}$, is defined as: ${ }^{5}$

$$
\begin{aligned}
F_{e} & =(T \cos \alpha \cos \beta-D) \\
& =m \dot{V}-m g\left[\begin{array}{c}
\cos \phi \cos \theta \sin \alpha \cos \beta \\
+\sin \phi \cos \theta \sin \beta \\
-\sin \theta \cos \alpha \cos \beta
\end{array}\right]
\end{aligned}
$$

where

$$
\begin{aligned}
\dot{V} & =\frac{u \dot{u}+v \dot{v}+w \dot{w}}{V} \\
\dot{u} & =a_{x}-q w+r v-g \sin \theta \\
\dot{v} & =a_{y}-r u+p w+g \sin \phi \cos \theta \\
\dot{w} & =a_{z}-p v+q u+g \cos \phi \cos \theta
\end{aligned}
$$

\section{Wind Tunnel}

Before fabrication of the LASRE pod, wind tunnel testing of a 4-percent scale model was completed to obtain stability and control increments and drag increments resulting from the pod. ${ }^{3}$ Wind tunnel data were obtained for the baseline SR-71 and the LASRE configuration. Increments were determined by subtracting the baseline SR-71 wind tunnel data from the LASRE configuration wind tunnel data.

\section{Simulation}

Flight simulation was used extensively in preparation for the LASRE flight tests. Two simulators were used; a workstation-based batch simulator and a piloted realtime full-cockpit simulator. Wind-tunnel determined stability and control increments and drag increments resulting from the LASRE pod were added to the baseline SR-71 aerodynamic model ${ }^{7}$ for use in the simulations. The batch simulation was used to obtain stability and control derivatives, trim elevon, and hinge moments predictions for the LASRE configuration. The real-time simulation was used for pilot training and performance estimation.

\section{$\underline{\text { Results and Discussion }}$}

This section of the paper focuses on stability and control and performance results. Results are discussed from baseline SR-71 flight tests without the LASRE pod installed, wind tunnel tests, flight simulation studies, and flight test with the LASRE pod installed.

\section{Baseline SR-71 Flight Results}

\section{Stability and Control}

In an effort to verify the existing SR-71 aerodynamic model, ${ }^{7}$ a series of stability and control doublet maneuvers were flown and analyzed for the baseline SR-71 aircraft. Figure 4 shows the Mach and altitude

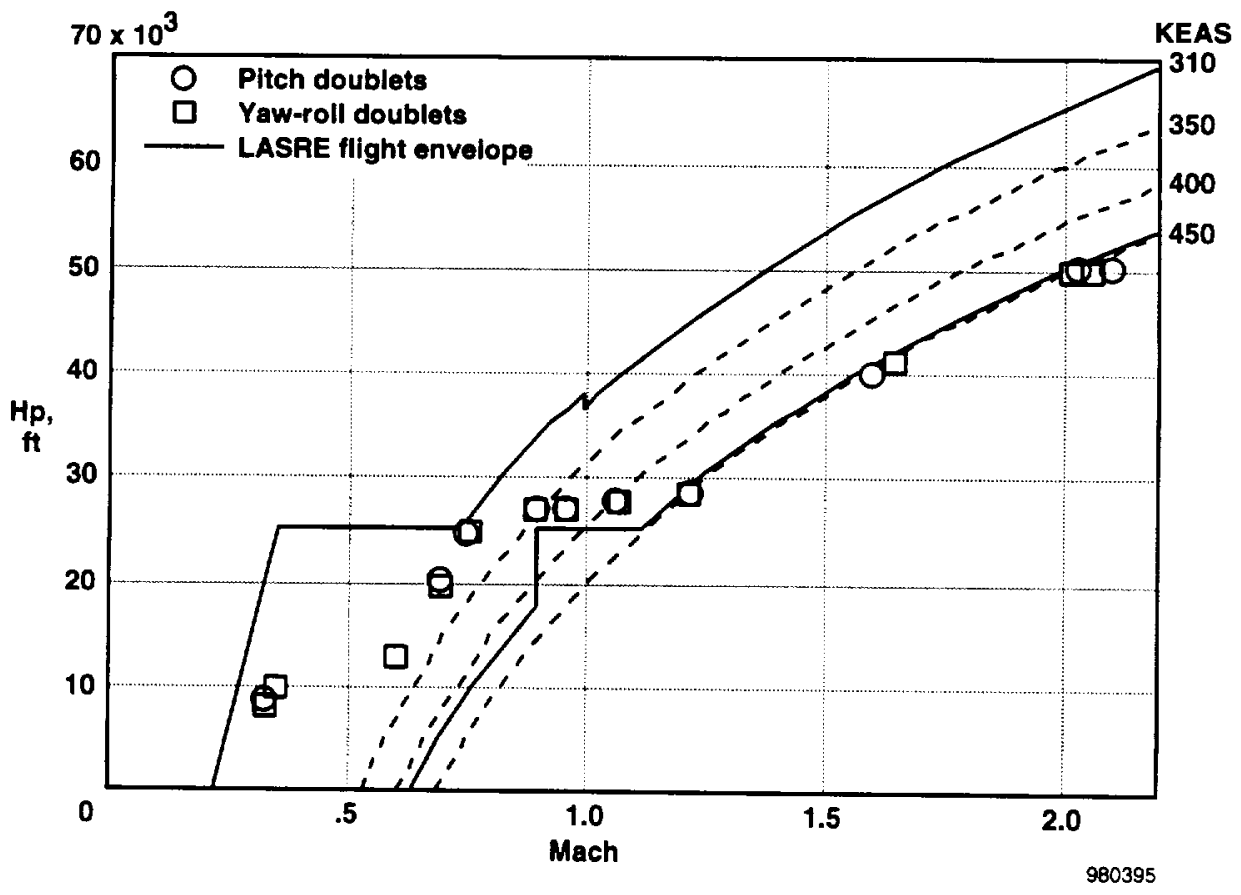

Figure 4. Flight conditions for baseline SR-71 stability and control test points. 
envelope for the LASRE configuration and the test conditions for the baseline SR-71 aircraft stability and control maneuvers shown in this report. The flight-derived stability and control derivatives for the baseline aircraft were compared with estimates from the batch simulator.

\section{Longitudinal Stability and Control}

The longitudinal stability derivative, $C_{m_{\alpha}}$, and the elevon effectiveness derivative, $C_{m_{\delta e}}$, for the baseline SR-71 aircraft are shown in figures 5 and 6 , respectively. Data were obtained at c.g.'s ranging from 19-24 percent $c$. The data in figures 5 and 6 were corrected to the moment reference used in the simulation which is at 25 percent $c$ (SR-71 F.S. 900). The circles in figure 5 represent flight-derived longitudinal stability derivatives and the squares represent simulation results for the same flight conditions. The aircraft is fairly flexible, ${ }^{7}$ and therefore some of the variability in the data is a result of test points at slightly different dynamic pressures. The solid line in figure 5 represents a hand fairing of the flight data using Cramér-Rao bounds ${ }^{5}$ as an indication of the maneuver quality. The dashed line represents a fit of the simulation data. As can be seen, there is fairly good agreement between the flight and simulation data. Figure 6 shows the elevon effectiveness, $C_{m_{\delta e}}$. Good agreement is observed between the flight and simulation data except at subsonic Mach numbers where the flight-derived effectiveness is as much as 20 -percent less than the simulation results.

\section{Lateral-Directional Stability and Control}

The lateral-directional stability and control derivatives for the baseline SR-71 aircraft are shown in figures 7-10. $C_{n_{\beta}}$ and $C_{n_{\delta r}}$ have been corrected to the moment reference. The directional stability derivative, $C_{n_{\beta}}$, shown in figure 7 shows slightly less stability than simulation from moderate subsonic to sonic Mach numbers. The dihedral effect, $C_{l_{\beta}}$, (fig. 8) shows reasonably good agreement with the largest deviation around Mach 1.2, where the flight data showed less stability. Figure 9 shows the rudder control effectiveness, $C_{n_{\delta r}}$, which agrees well with simulation, except subsonically where the flight-derived effectiveness is approximately 15-percent less than simulation. The aileron control effectiveness, $C_{l_{\delta a}}$, shown in figure 10 , agreed well with simulation except for slight differences at high subsonic Mach numbers.

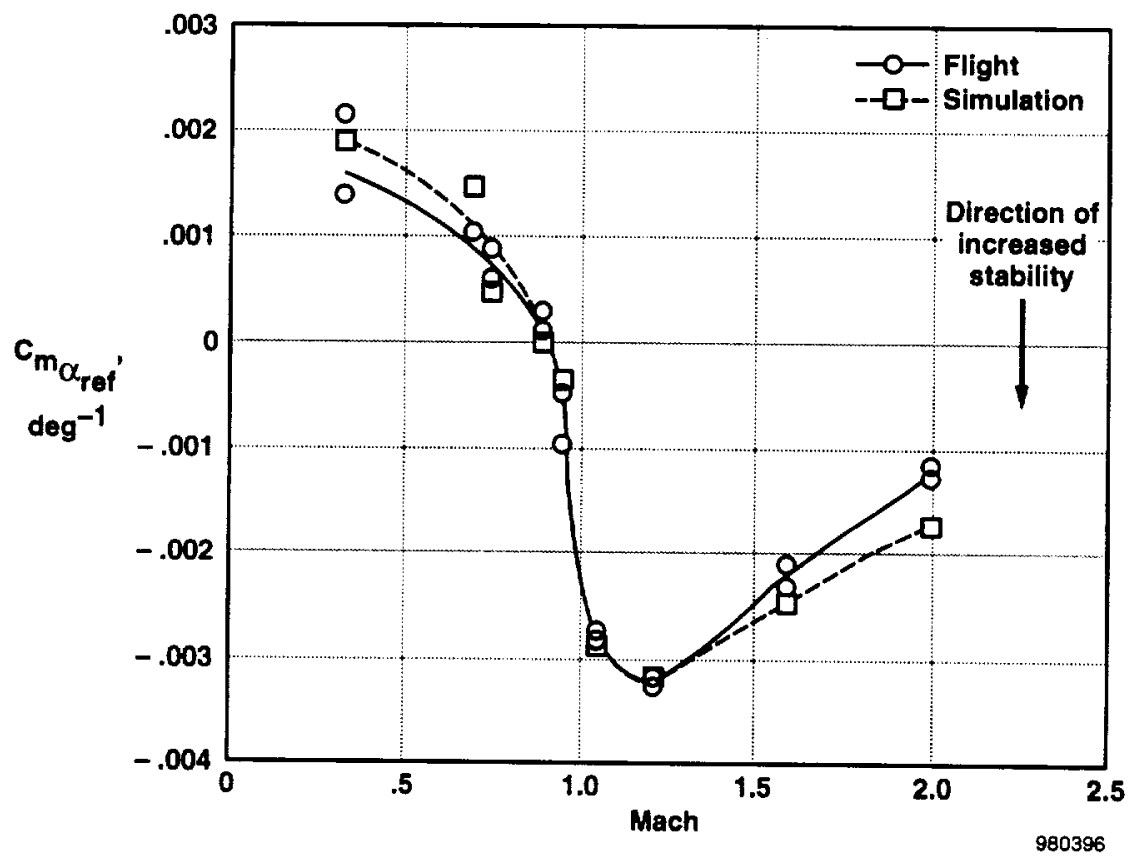

Figure 5. Baseline SR-71 longitudinal stability derivative corrected to the moment reference. 


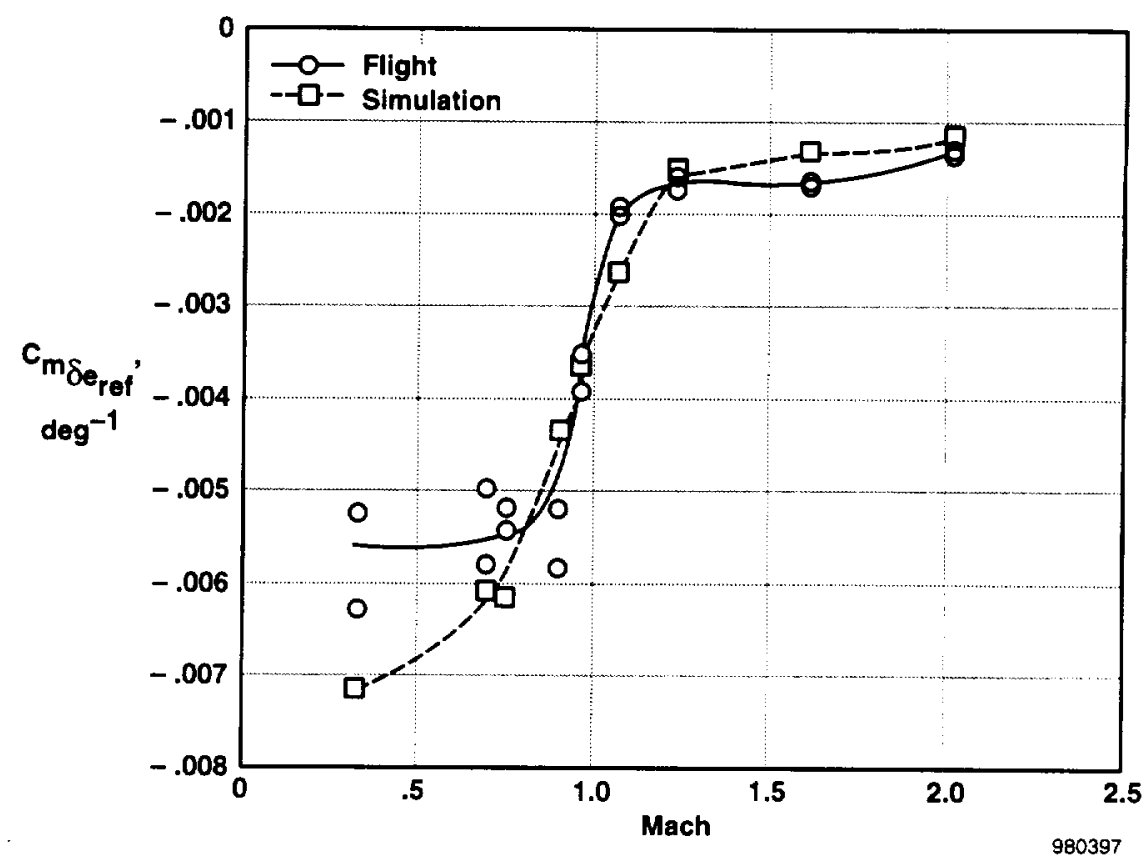

Figure 6. Baseline SR-71 elevon effectiveness derivative corrected to the moment reference.

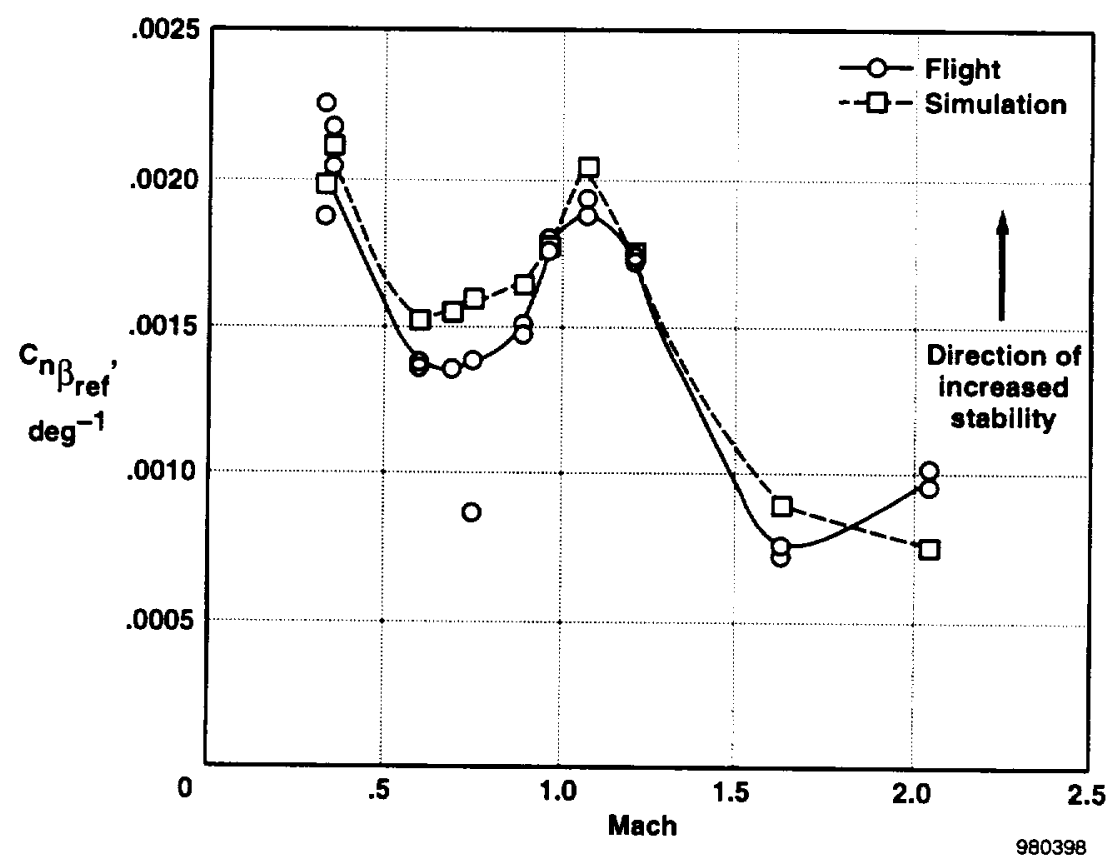

Figure 7. Baseline SR-71 directional stability derivative corrected to the moment reference. 


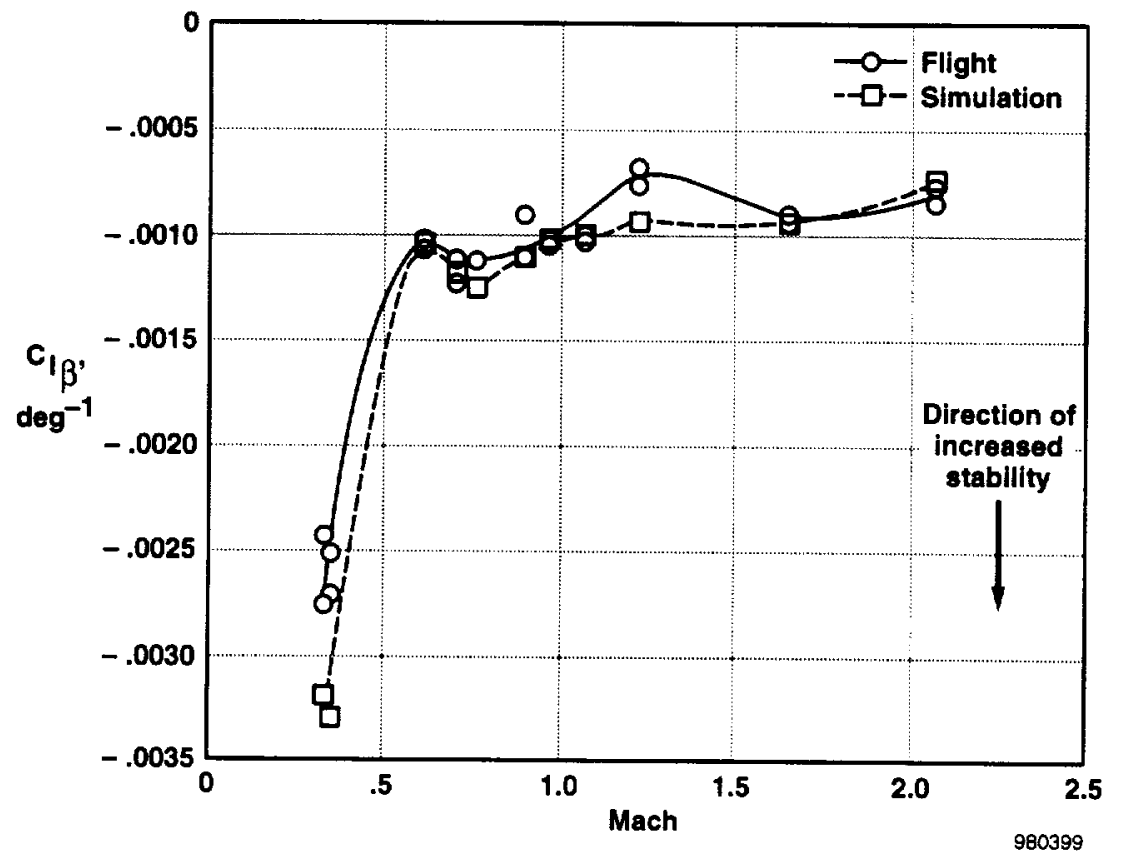

Figure 8. Baseline SR-71 dihedral effect.

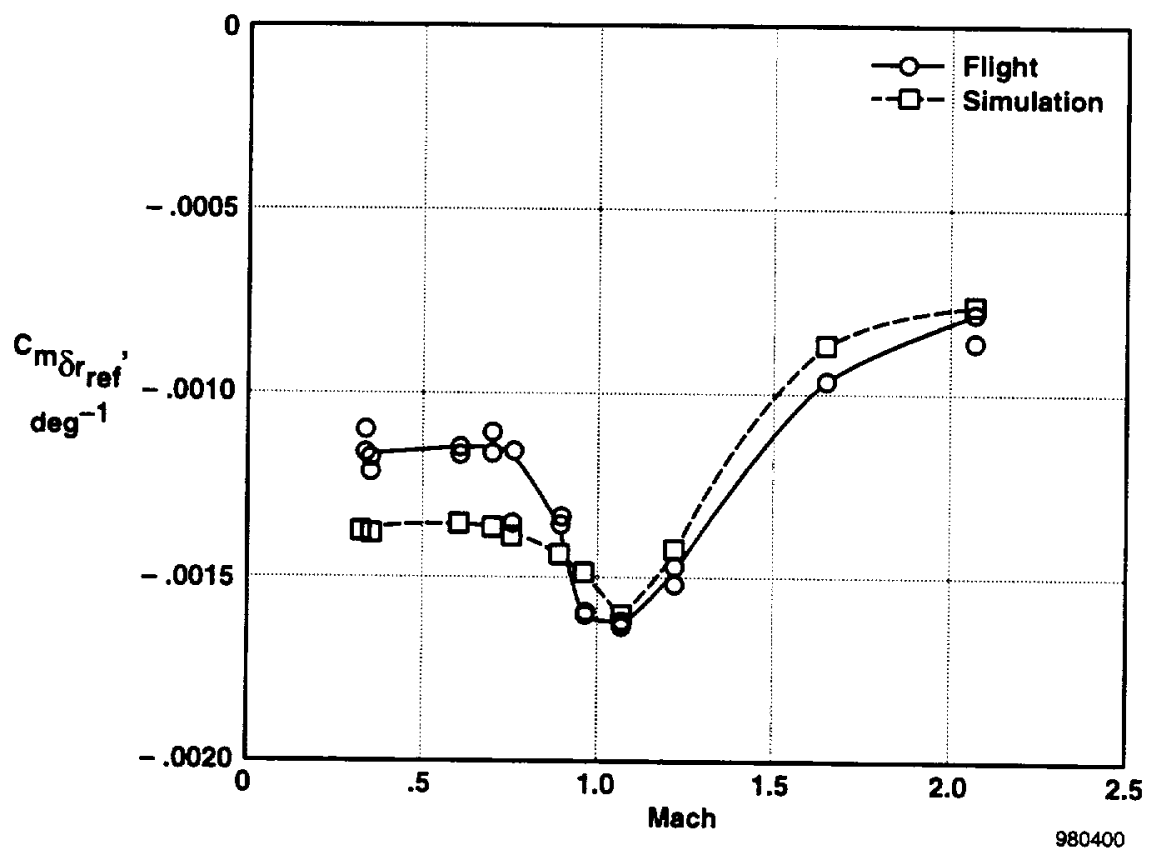

Figure 9. Baseline SR-71 rudder effectiveness derivative corrected to the moment reference. 


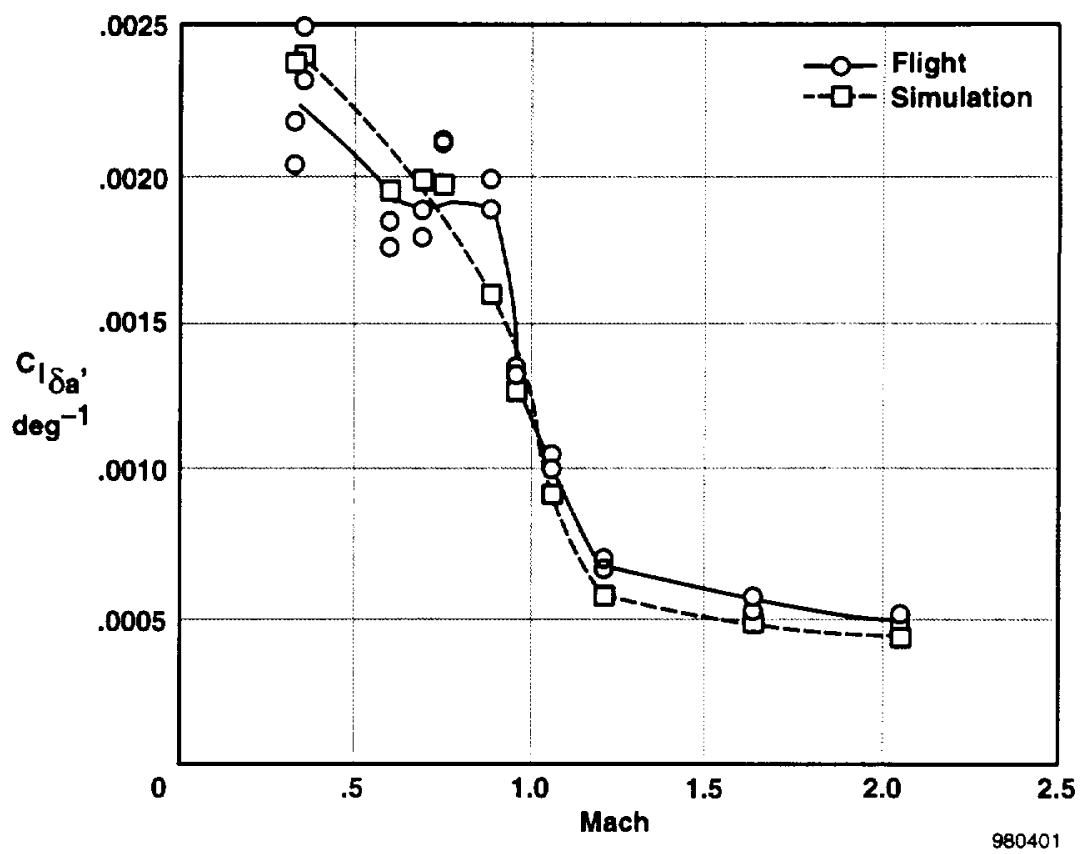

Figure 10. Baseline SR-71 aileron effectiveness derivative.

\section{Performance}

The performance of the J58 engine is strongly linked to ambient air temperature. Baseline SR-71 flight data collected from different days with different ambient temperatures were analyzed in order to evaluate the excess thrust model in the simulator. Excess thrust performance from the flight data was obtained using equation 13 and was compared with the simulations for the same flight conditions. In all cases, the simulator overpredicted the excess thrust for Mach numbers between 0.95 and 1.2; in some cases by as much as $5000 \mathrm{lb}$. Two full-afterburner level accelerations at an altitude of $30,000 \mathrm{ft}$ are shown in figure 11 . In one case the ambient temperature was $6^{\circ} \mathrm{C}$ above the standard day temperature and in the other case it was $3.6^{\circ} \mathrm{C}$ below the standard day temperature. As observed, the simulator overpredicted excess thrust in both cases, and more so for the warmer day. Unfortunately, it was not practical to improve the simulator performance fidelity because of the complexity of the aerodynamic and propulsion models combined with the scarcity of flight-to-simulation performance comparisons.

\section{LASRE Pod Wind Tunnel Predictions.}

Stability and Control

Wind tunnel tests predicted that the LASRE pod would cause a significant change in pitching moment transonically. ${ }^{3}$ For $4^{\circ} \alpha$, typical trim $\alpha$ for the SR-71, the wind tunnel test predicted a maximum noseup increment at Mach 1.05 and a significant nosedown increment at Mach 1.2 (fig. 12).

\section{Performance}

Figure 13 shows the wind-tunnel predicted trimmed drag for the LASRE configuration plotted with the baseline SR-71 trimmed drag for $4^{\circ} \alpha$. As observed, wind tunnel results showed that the addition of the LASRE pod resulted in a maximum drag rise of nearly 70 percent.

\section{Simulation Studies}

\section{Stability and Control}

Simulations showed that obtaining trimmed flight required elevator deflections of approximately $5^{\circ}$ noseup at Mach 1.2 at the altitudes used for transonic acceleration. The simulator showed that this trim requirement approached the maximum capability of the elevon actuator power if one of the two SR-71 hydraulic systems were to fail.

\section{Performance}

The LASRE configuration performance capability was analyzed by wings-level accelerations performed in 


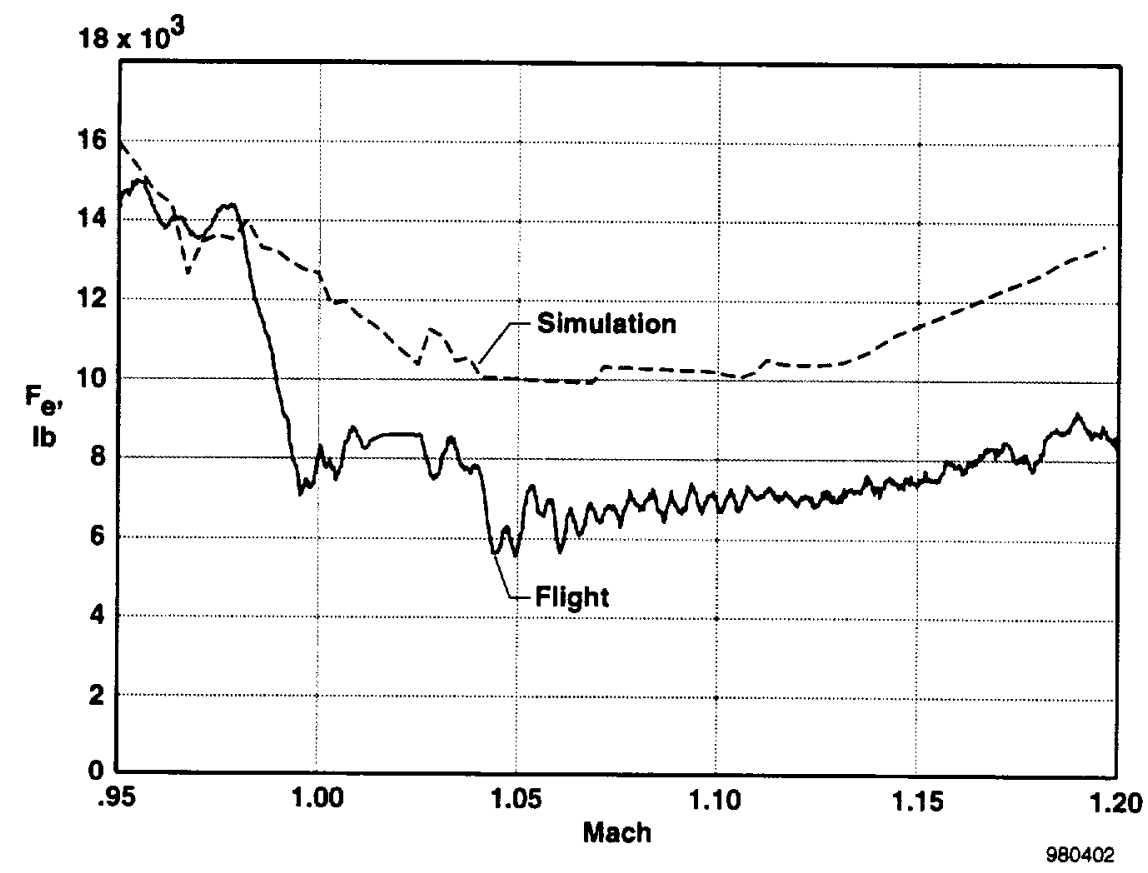

(a) Ambient temperature $6{ }^{\circ} \mathrm{C}$ greater than standard day temperature.

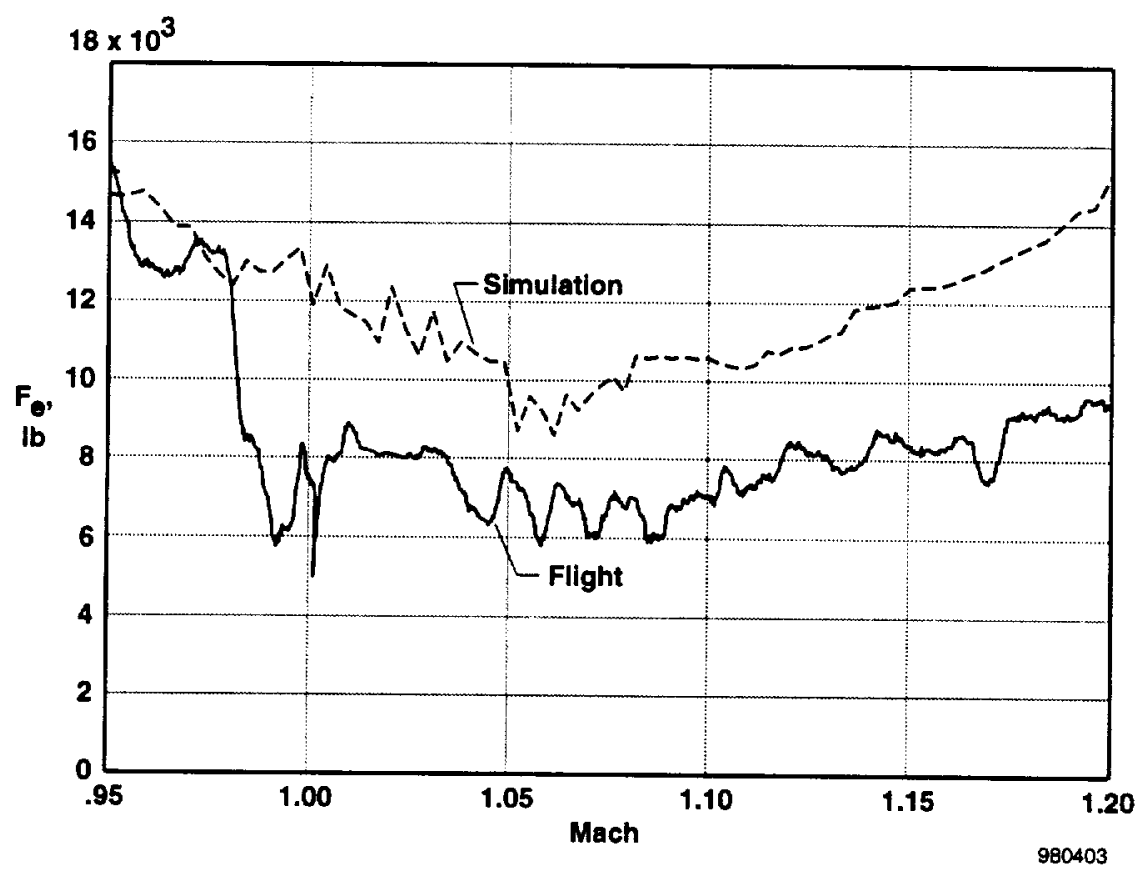

(b) Ambient temperature $3.6^{\circ} \mathrm{C}$ less than standard day temperature.

Figure 11. Flight and simulation excess thrust results for the baseline SR-71 aircraft during level accelerations at $30,000 \mathrm{ft}$ altitude. 


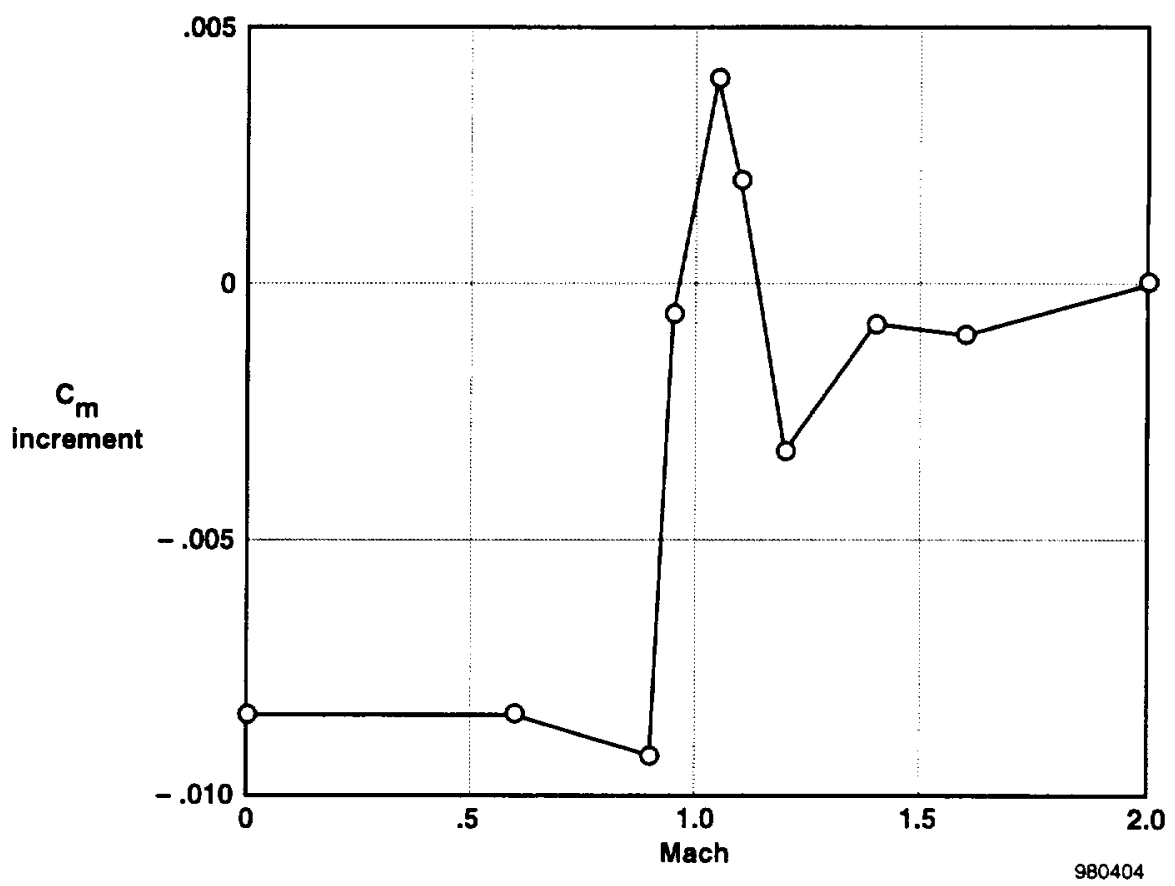

Figure 12. Predicted $C_{m}$ increment resulting from the LASRE pod at $4^{\circ} \alpha$.

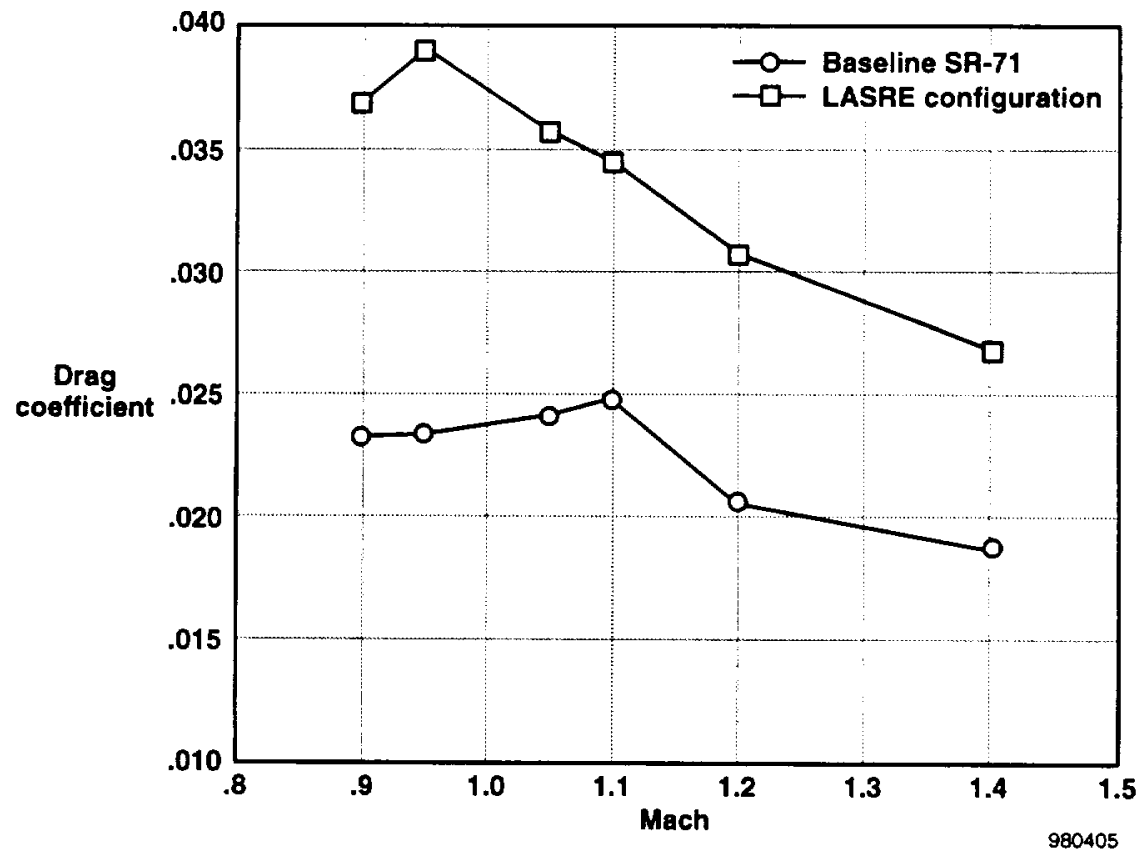

Figure 13. Predicted trimmed drag of the LASRE configuration compared to the baseline SR-71. 
the simulator using the standard day atmospheric temperature profile. ${ }^{8}$ Under standard day conditions, the LASRE configuration was predicted to be capable of obtaining the original project requirements of Mach 3.2 test points. The performance pinch point is during transonic acceleration where excess thrust is at a minimum. The addition of the LASRE pod added as much as 70-percent more drag transonically than for the baseline SR-71. Figure 14 shows a simulation of fuel usage during a $25,000 \mathrm{ft}$. altitude level acceleration to 450 knots equivalent airspeed (KEAS) (Mach 1.12) followed by a constant KEAS climb to $31,800 \mathrm{ft}$ (Mach 1.3). Results were obtained for a range of temperatures between $10^{\circ} \mathrm{C}$ warmer than a standard day and $10^{\circ} \mathrm{C}$ colder than a standard day. As can be seen, an additional $11,000 \mathrm{lb}$. of fuel was required on the $+10^{\circ} \mathrm{C}$-day as compared to a standard day. As discussed previously, the transonic performance simulation was already suspect (fig. 11). Given the uncertainties in the performance simulation for the baseline SR-71 and the drag predictions for the addition of the LASRE pod, it was again left for flight test to provide the definitive performance answers.

\section{Flight Envelope Expansion}

Both flutter envelope expansion and stability and control envelope expansion were required prior to firing the aerospike rocket in flight. Flutter clearance consisted of a series of longitudinal pitch pulses during level accelerations or constant KEAS climbs. This report will not discuss the flutter clearance except to say that the required flight envelope was successfully cleared for flutter with no concerns. Stability and control envelope expansion included a series of pitch doublets and yawroll doublets. ${ }^{5}$ In some cases the pilot would stabilize the aircraft at a specified Mach and altitude and perform a series of doublets. In other cases, the pilot would perform a single doublet at a specified Mach number during an acceleration or deceleration. In all cases, these doublets demonstrated the acceptability of the LASRE configuration handling qualities in real-time. The maneuvers were analyzed postflight to obtain stability and control derivatives for the LASRE configuration. Because of structural concerns associated with the pod, the doublet size was limited by angular acceleration to be less than $8 \% \mathrm{sec}^{2}$ pitch acceleration, $4.5 \% \mathrm{sec}^{2}$ yaw acceleration, and $43 \% \mathrm{sec}^{2}$ roll acceleration.

The simulation-predicted transonic noseup pitch trim requirement was shown to approach the limit of elevon actuator power available if one of the two SR-71 hydraulic systems should fail. This potentially dangerous situation required limiting the aircraft speed and c.g. envelopes until flight envelope expansion determined the actual pitching moments. The flight

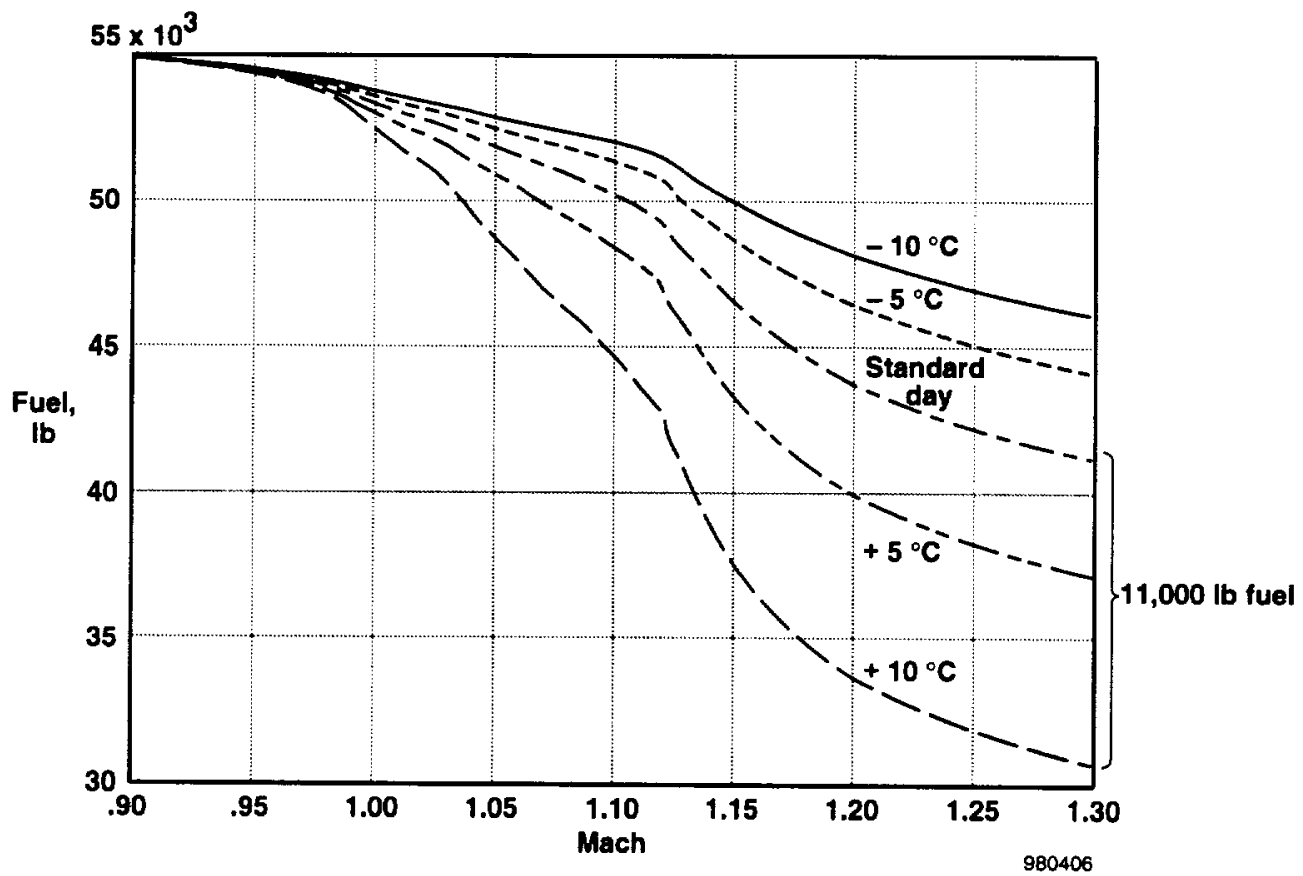

Figure 14. Simulation results of the performance effects as a result of ambient temperature during a transonic acceleration and climb to Mach 1.3. 
envelope was limited to avoid a flight configuration that could not recover from a failure of one of the two hydraulic systems. For this reason, instrumentation was added to the inboard elevons and to the left outboard elevon to measure hydraulic actuator pressures for the elevon trailing-edge-up deflections. Real-time flight monitoring of these hydraulic pressures was done to ensure that the aircraft would not fly into a flight regime where it could become hinge-moment limited in the event of one hydraulic system failure.

\section{LASRE Configuration Stability and Control Flight Results}

The stability and control test points presented in this report for the LASRE configuration are shown in figure 15. It should be noted that the pitch and roll stability and control derivatives are a function of the equivalent airspeed because of the flexibility of the SR-71 aircraft. ${ }^{7}$ The test points represented by the open symbols in figure 15 were chosen so that the derivative results could be plotted as a function of Mach number without confusion caused by the flexibility effects. The solid points correspond to lower KEAS flight conditions at which the aerospike rocket test firings are planned.

\section{Longitudinal Stability and Control}

The longitudinal stability and elevon control effectiveness derivatives are shown in figures 16 and 17.
Again, these results were corrected to the 25 percent $c$ moment reference location. The circles represent flight determined derivatives and the squares represent derivatives obtained from the batch simulation. The solid line is the Cramér-Rao-based hand fairing of the flightdetermined derivatives for the test points shown in figure 15 that are not rocket test points. The dashed line is the fit of the simulation predictions for the LASRE derivatives at the same test points. The solid symbols represent the flight and simulation derivatives for the lower KEAS rocket test points shown in figure 15 . As can be seen in figure 16 , flight determined values of $C_{m_{\alpha}}$ agreed fairly well with the simulation predictions. Supersonically, flight data at the lower KEAS rocket test points showed the same derivative values as the higher KEAS data, whereas the simulations indicated that lower KEAS effects would improve the stability. As observed in figure 17, at transonic Mach numbers, flight derived $C_{m_{\delta e}}$ agreed fairly well with the predictions. Subsonically, the elevon effectiveness is as much as 20-percent less than the predictions. Comparing figure 17 with figure 6 , the aerodynamic model of elevon effectiveness for the baseline SR-71 was also in error subsonically at approximately the same magnitude.

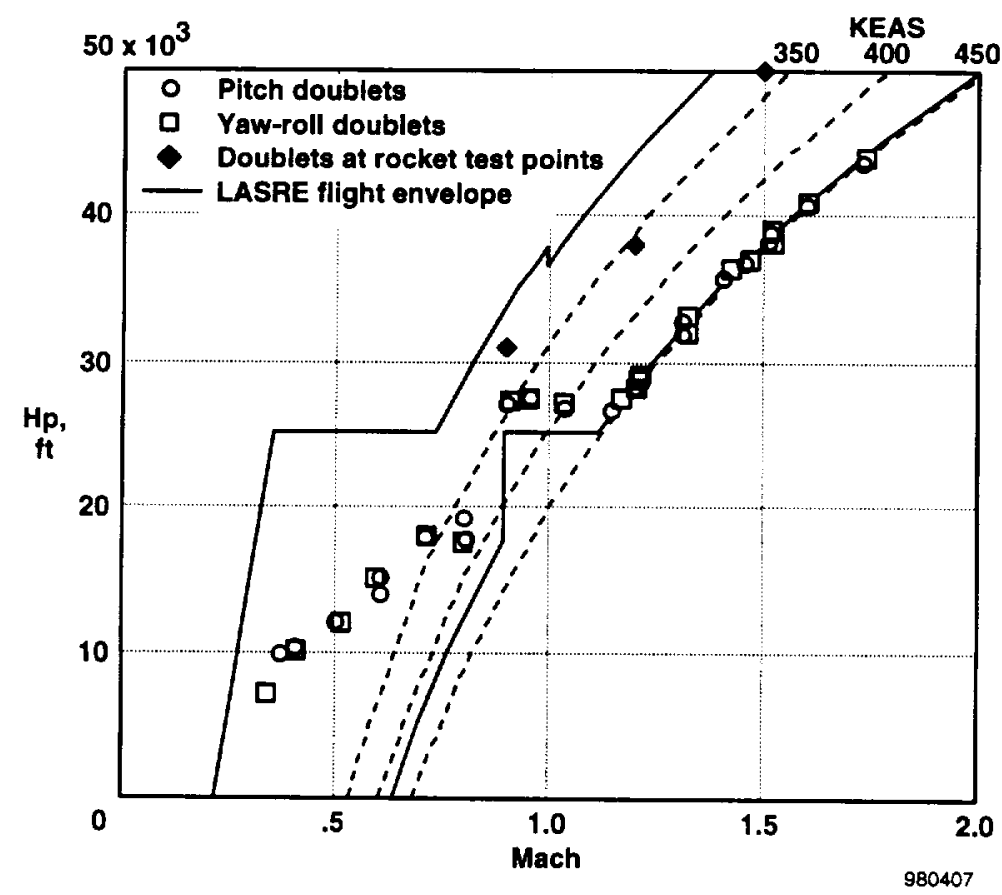

Figure 15. Flight conditions for LASRE configuration stability and control test points. 


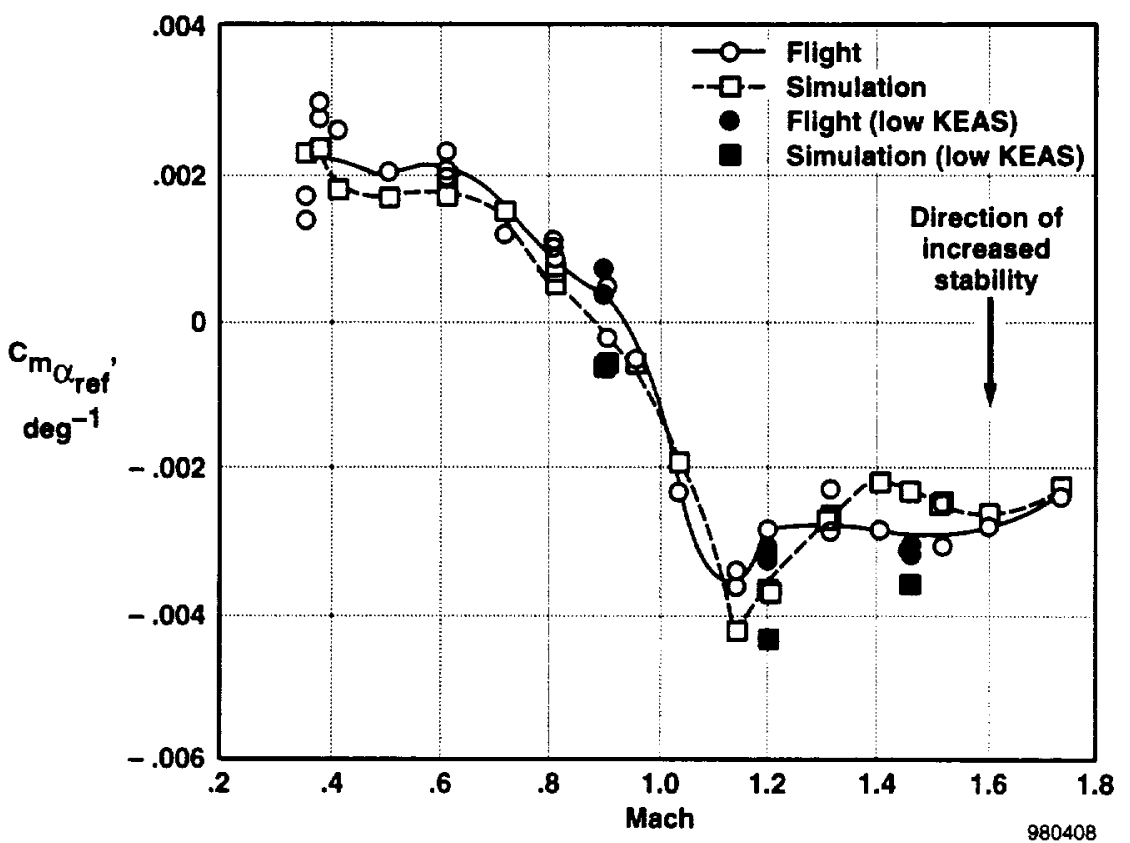

Figure 16. LASRE longitudinal stability derivative corrected to the moment reference.

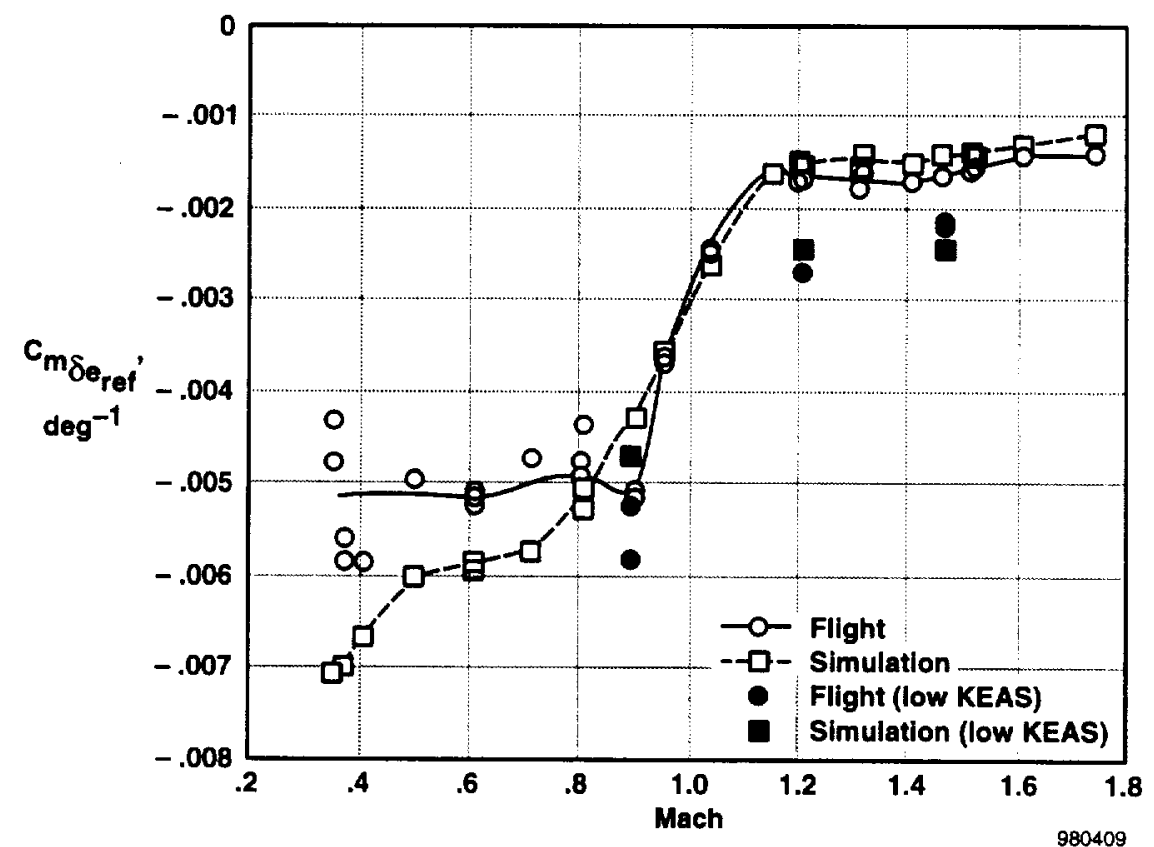

Figure 17. LASRE elevon effectiveness derivative corrected to the moment reference. 


\section{Pitch Trim}

Transonic pitch trim authority was a concern because of wind tunnel predictions. A comparison between simulation prediction and flight measured trim elevon is shown in figure 18 using data from two different flights. The actual amount of trim required is a function of c.g. and therefore varies slightly between flights when plotted against Mach number. The data points plotted are for wings-level flight with a normal load of approximately $1-g$. The flight data were low-pass filtered at $0.1 \mathrm{rad} / \mathrm{sec}$ to remove the transient effects. In general, more nosedown trim was required than had been predicted throughout the Mach range. The trim agreed fairly well in the Mach 1.05 to 1.15 range. The largest change was at Mach 0.9. At this speed close to $1^{\circ}$ nosedown trim was required compared with a $2^{\circ}$ noseup trim requirement that had been predicted. Also, at Mach 1.2, $2^{\circ}$ less noseup trim was required. Since the transonic estimates of $C_{m_{\alpha}}$ and $C_{m_{\delta e}}$ (figs. 16 and 17) agreed fairly well with predictions, the differences seen in transonic elevon deffections with simulator predictions were solely a result of mispredicting the zero-lift pitching moment increment in the wind tunnel test.

\section{Pitching Moment}

The batch simulator was used to determine the increment in $C_{m}$ that was required to make the simulation elevon deflection match the flight value at a given flight condition. The results depended on the elevon control effectiveness, $C_{m_{\delta e}}$, and the longitudinal stability, $C_{m_{\alpha}}$. Based on figure $16, C_{m_{\alpha}}$ from flight agreed well with predictions. Figure $17^{\alpha}$ showed that $C_{m_{\delta}}$ agreed well, except at subsonic speed. Based on figure 17, the LASRE simulator value for $C_{m_{\delta e}}$ was incremented as a function of Mach according to the following table:

Table 1. Flight determined $C_{m_{\delta e}}$ increment added to the simulation.

\begin{tabular}{c|cccc}
\hline \hline Mach & 0 & 0.68 & 0.9 & 3.2 \\
\hline$C_{m_{\delta e}}$ increment & 0.0014 & 0.0014 & 0.0000 & 0.0000 \\
\hline \hline
\end{tabular}

Using the batch simulator, the pitching moment increment caused by the LASRE pod was obtained from flight and was compared with the preflight prediction in figure 19. There are two regions of significant change. The region from $\mathbf{M}=0.9$ to $\mathbf{M}=1$ shows a considerably larger pitch-up increment and the region around $M=1.2$ shows no pitch-down increment.

\section{Actuator Pressures}

As a result of concerns in reaching hinge-moment limits during transonic acceleration, elevon hydraulic

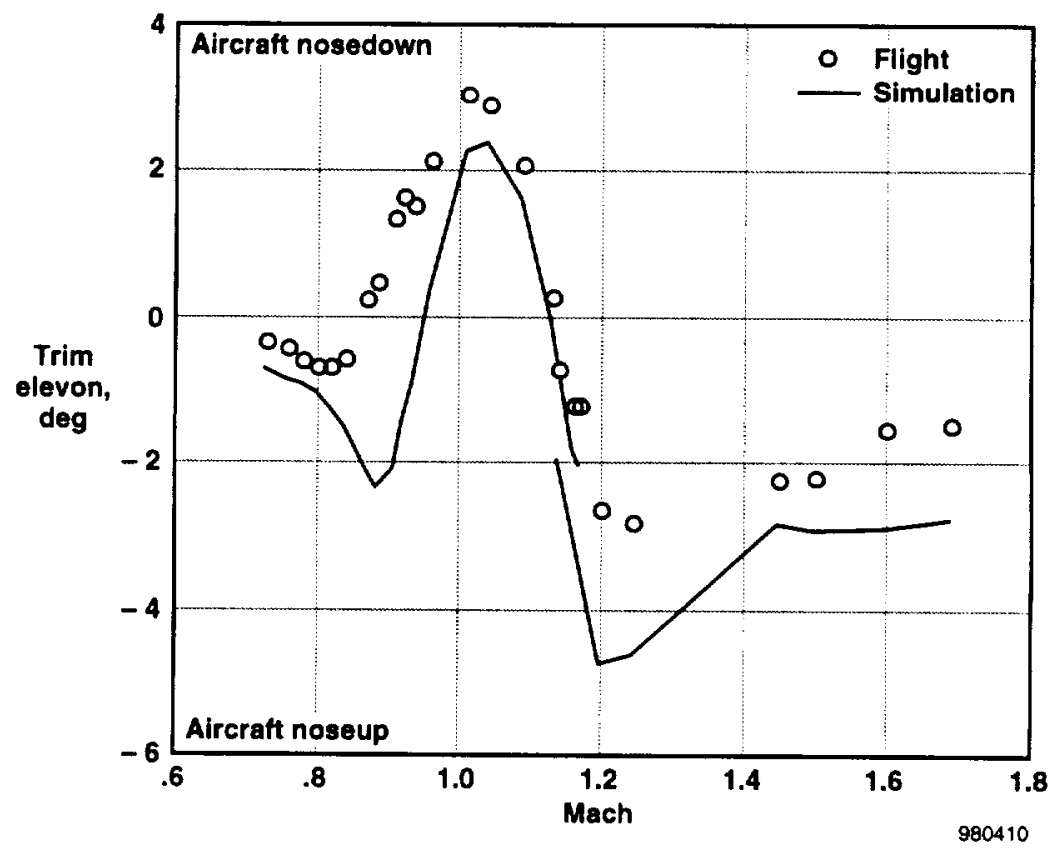

Figure 18. Elevon trim comparison between flight and simulation predicted results. 


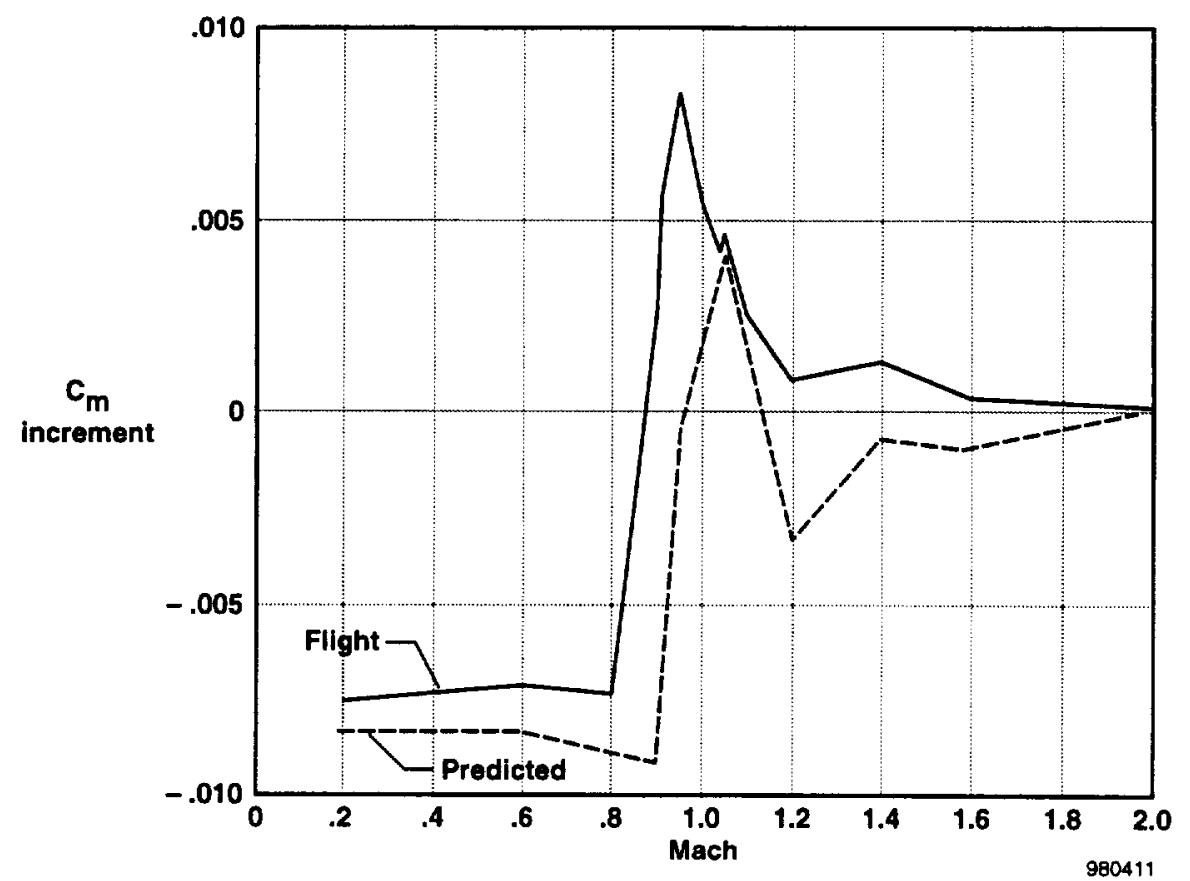

Figure 19. Pitching moment increment as a result of the LASRE pod, obtained from flight data and wind tunnel predictions.

actuator pressures were measured and observed during flight. Figure 20 shows the outboard and inboard hydraulic pressure measurements during wings-level, 1-g trim conditions. With zero hinge moment, the pressure reads $1000 \mathrm{lb} / \mathrm{in}^{2}$. The upper limit for safe operation was $2100 \mathrm{lb} / \mathrm{in}^{2}$. As can be seen in figures 20(a) and 20(b), the limit was not reached by either the outboard or inboard elevons. The data below Mach 1 and above Mach 1.2 show that the actuator pressures were lower than predicted, which is consistent with the reduced noseup trim requirement (fig. 18). The outboard elevon pressure did indicate that with one hydraulic failure the elevon would be hinge-moment limited at Mach 1.0 to 1.04 in nosedown capability (i.e. the pressure was less than the $500 \mathrm{lb} / \mathrm{in}^{2}$ minimum criteria). This was not a safety concern for two reasons: (1) the inboard elevons were not hinge-moment limited and therefore trim authority still existed, and (2) if both inboard and outboard elevons did become hingemoment limited the aircraft would pitch up slowly and decelerate to a point at which the control authority would return.

\section{Lateral-Directional Stability and Control}

The angle of sideslip derivatives are shown in figures 21 and 22. For the most part both the directional stability, $C_{n_{\beta}}$, and dihedral effect, $C_{l_{\beta}}$, were less stable than the simulator predictions had indicated. Figure 21 shows $C_{n_{\beta}}$ as much as 30 -percent less than predicted. As discussed in reference 7 , there were no flexibility corrections for the yaw axis. The flight data verified this, as there was little difference between the data at the low KEAS test points and at elevated KEAS test points (with the exception of one maneuver at Mach 0.9). Figure 22 shows $C_{l_{\beta}}$ as much as 50-percent less stable than predictions. Comparisons with figures 7 and 8 showed that similar trends in misprediction were seen in the baseline SR-71 aerodynamic model.

The rudder and aileron effectiveness control derivatives are shown in figures 23 and 24 . The rudder effectiveness, $C_{n_{\delta r}}$, was less than predicted below Mach 1.3 and the aileron effectiveness, $C_{l_{\delta a}}$, showed good agreement. Subsonically, the rudder effectiveness misprediction was of the same magnitude as the misprediction of the baseline SR-71 rudder effectiveness (fig. 9). However at the low supersonic Mach numbers the misprediction in $C_{n_{\delta}}$ is caused by the misprediction of the pod effect from the wind tunnel. At worst, the rudder effectiveness was 23-percent less than predicted at Mach 1.05 . 


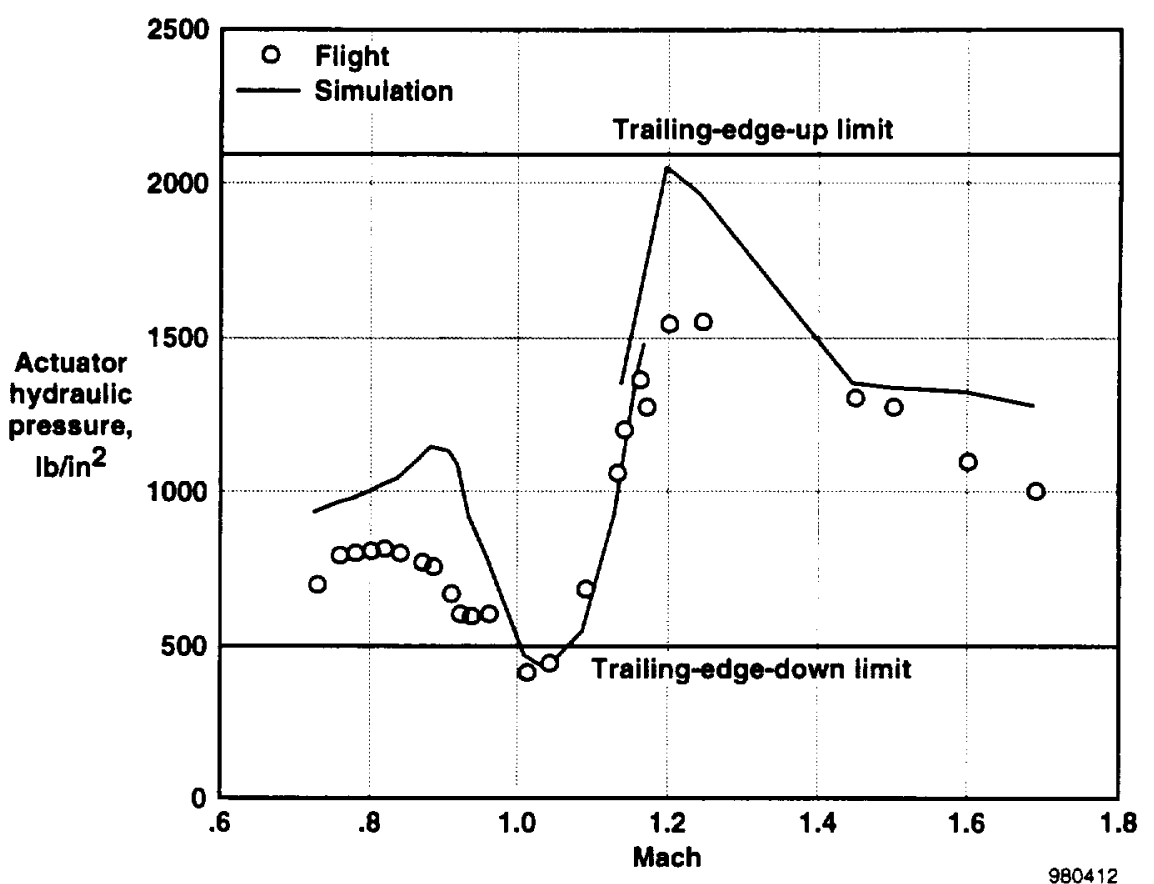

(a) Outboard elevon.

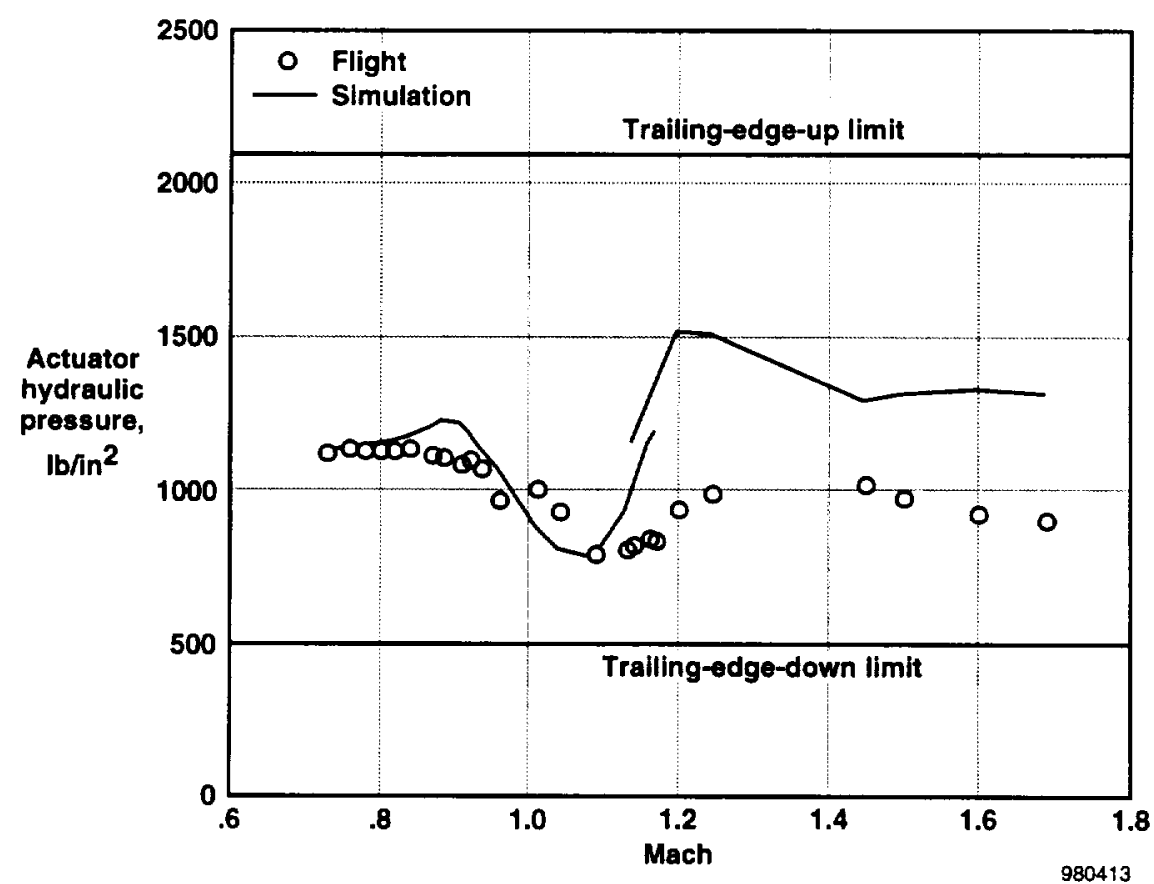

(b) Inboard elevon.

Figure 20. Elevon hydraulic pressure. 


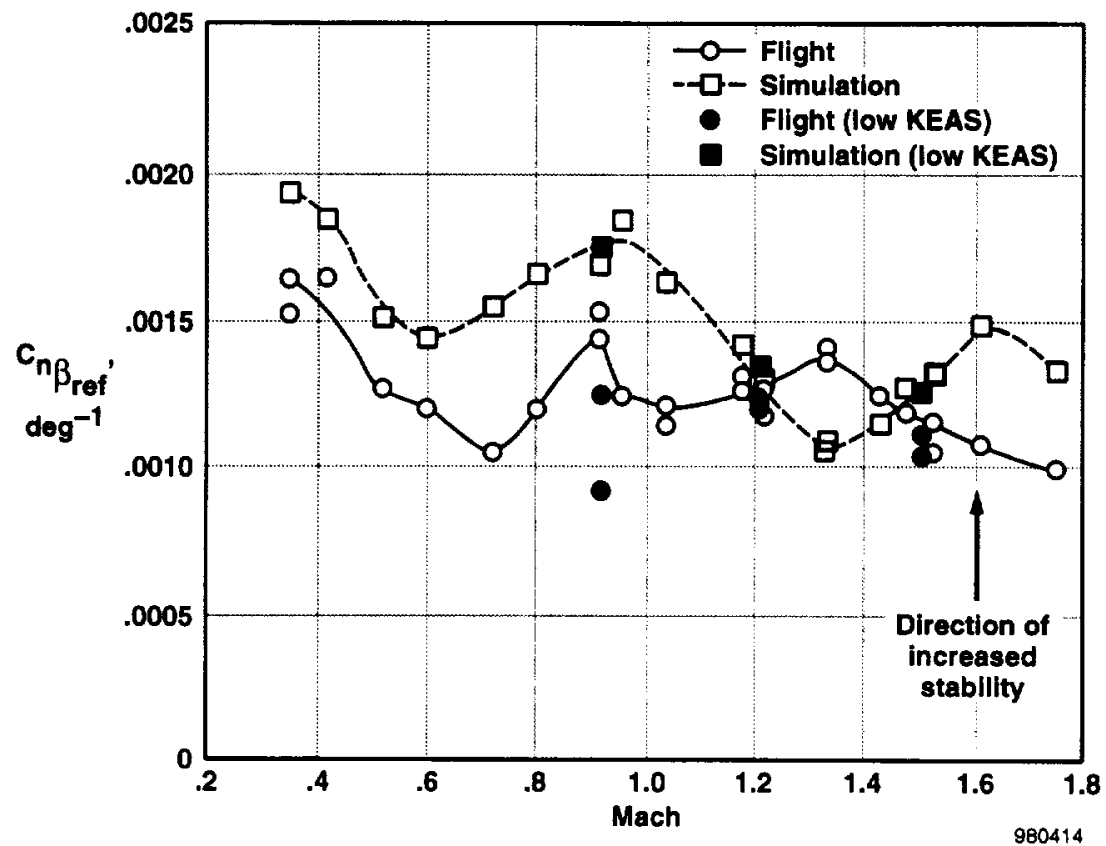

Figure 21. LASRE directional stability derivative corrected to the moment reference.

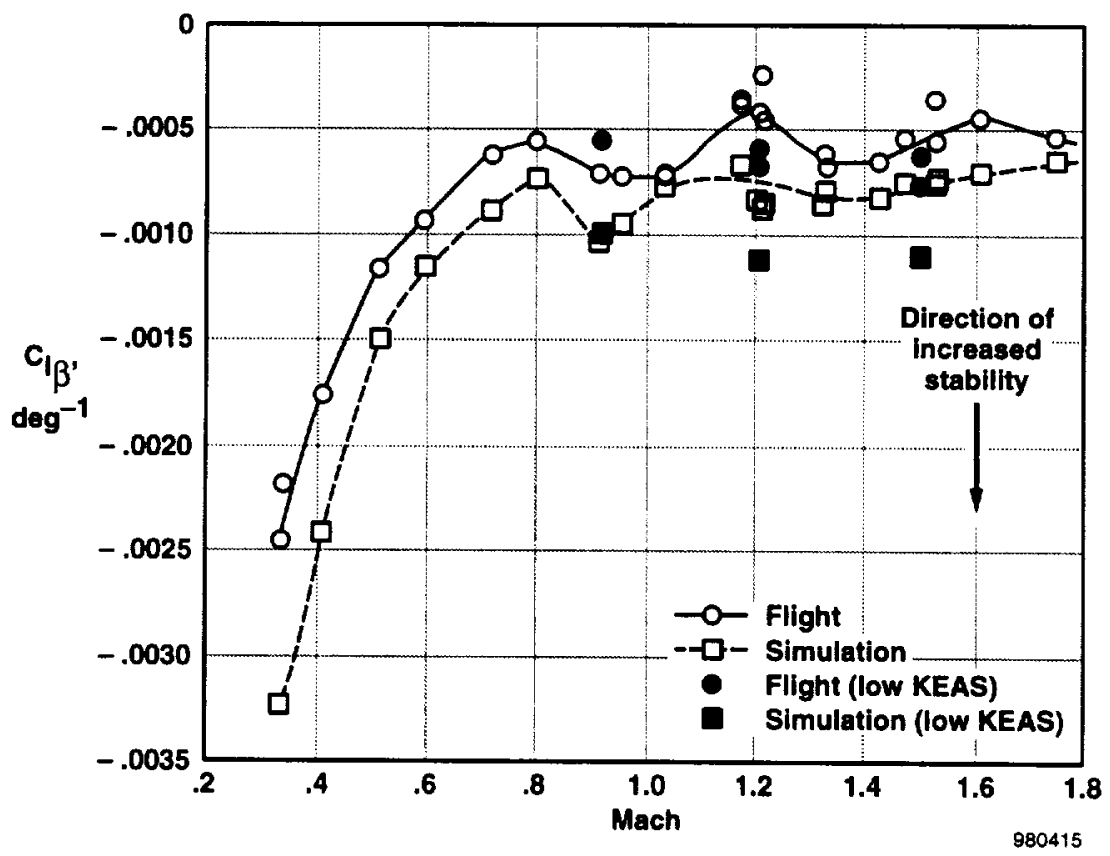

Figure 22. LASRE dihedral effect. 


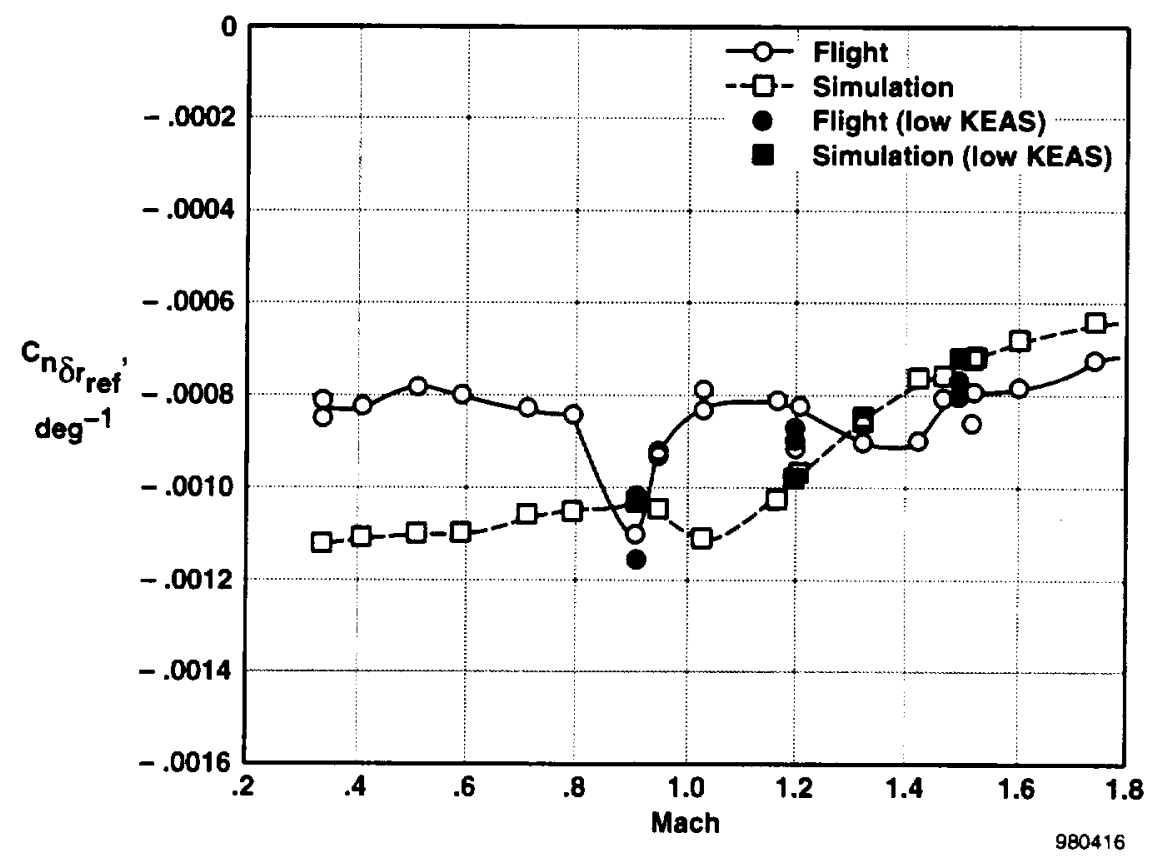

Figure 23. LASRE rudder effectiveness derivative corrected to the moment reference.

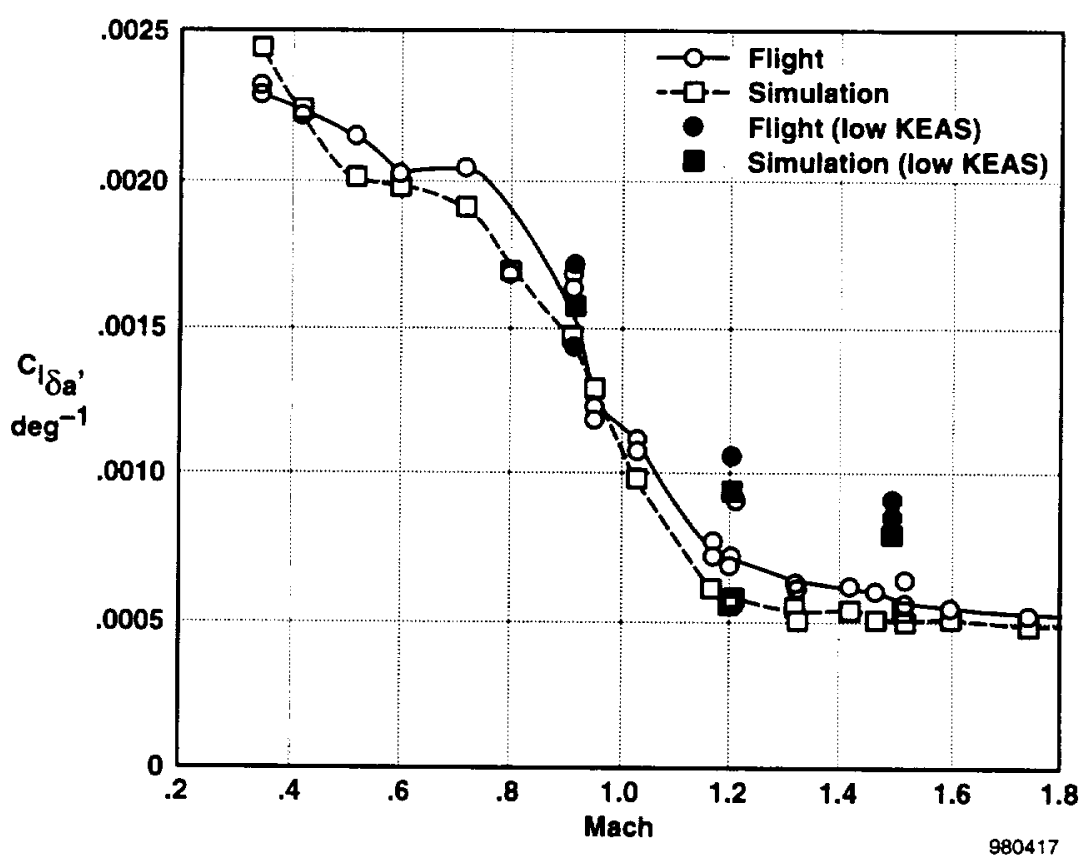

Figure 24. LASRE aileron effectiveness derivative. 


\section{$\underline{\text { Simulation Update }}$}

Flight determined corrections to $C_{m}, C_{m_{\delta_{e}}}, C_{n_{\mathrm{B}}}$, $C_{l_{\beta}}$, and $C_{n_{\delta r}}$ were input into the piloted simulation for handling qualities evaluations. These evaluations included aerospike rocket firings at the specified test conditions and emergency situations such as engine and hydraulic system failures. In all cases, the simulations showed acceptable handling qualities and that the aircraft responses were within acceptable load factor and angle of sideslip limits.

\section{LASRE Configuration Performance Flight Results}

The most critical part of the flight envelope pertaining to performance was the transonic acceleration. The LASRE configuration had significant excess thrust at all Mach numbers except at transonic conditions. The first LASRE flight occurred at the end of October on an unseasonably warm day. A $27,000 \mathrm{ft}$ altitude level acceleration was used to accelerate the aircraft through the transonic Mach numbers while simultaneously obtaining flutter as well as stability and control test data. The free-stream temperature at $27,000 \mathrm{ft}$ was $9{ }^{\circ} \mathrm{C}$ warmer than a standard day. As a result of the hot temperature, excess thrust was so low that the aircraft was only able to accelerate to Mach 1.17 before reaching the fuel-low limit.
The flight data showed that the LASRE configuration accelerated at a rate significantly worse than simulation results had predicted (fig. 25). The simulation, which took into account the flight day temperature and the flight-derived $C_{m}$ increments presented in figure 19 , underestimated the required fuel usage by $10,000 \mathrm{lb}$. To compensate for this discrepancy, an effort was made to increase the fidelity of the simulator. The excess thrust computed from flight and simulator data is shown in figure 26. The excess thrust increment between flight and simulator data was compared with the predicted trimmed drag increment caused by the pod (fig. 13) in figure 27. The excess thrust increment was equivalent to a 40-percent pod drag increase at Mach 0.98 and approximately 25-percent pod drag increase at Mach 1.02 and higher. This excess thrust increment was subtracted from the simulator performance model and the acceleration was simulated using the same ground track as the flight data. As shown in figure 28, the simulator results now agreed well with the flight results.

The second LASRE flight occurred on a nearly standard temperature day. A level acceleration was performed at an altitude of $25,000 \mathrm{ft}$ where the ambient temperature was just $1{ }^{\circ} \mathrm{C}$ above the standard day temperature. The fuel performance plot is shown in figure 29 and compared with simulation results for accelerations at $+4{ }^{\circ} \mathrm{C}$ and $+7^{\circ} \mathrm{C}$. The simulation results

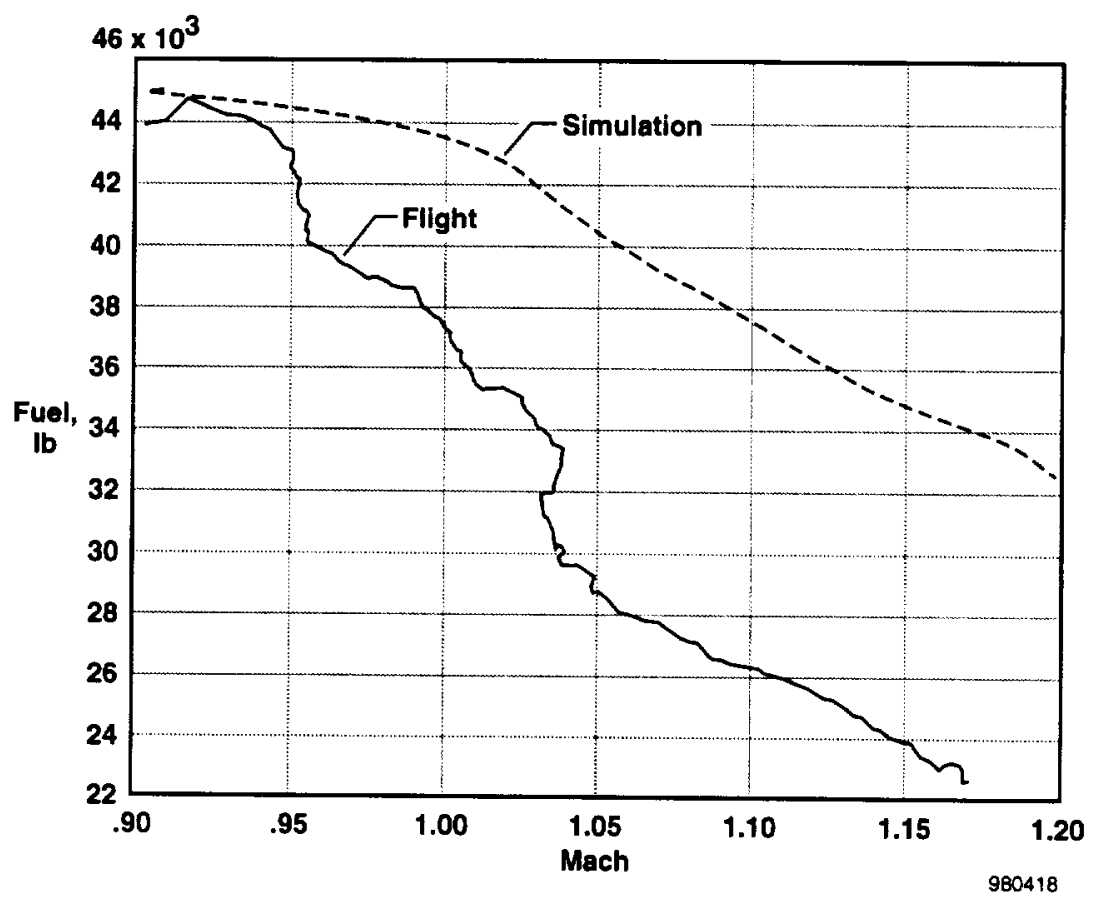

Figure 25. Fuel performance for a transonic acceleration at $27,000 \mathrm{ft}$. 


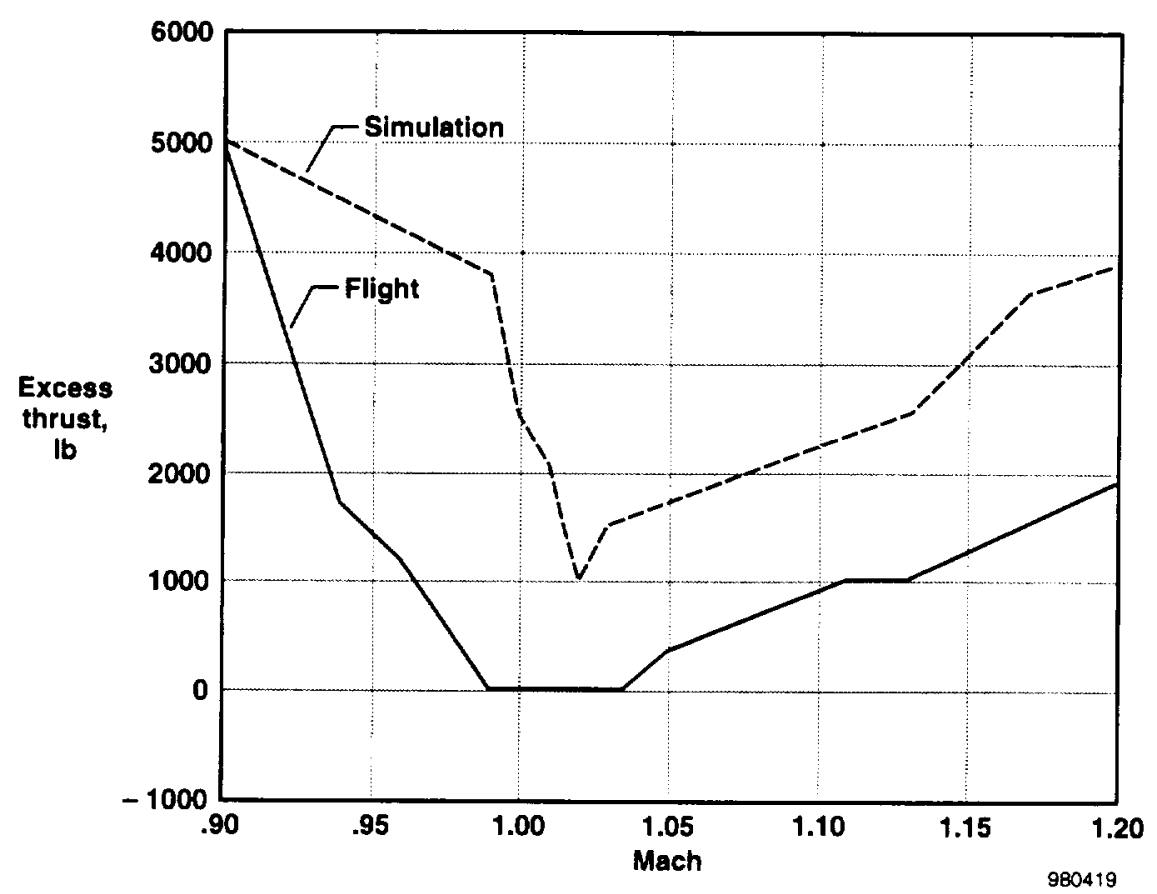

Figure 26. Flight and simulator excess thrust results for transonic acceleration at an altitude of $27,000 \mathrm{ft}$.

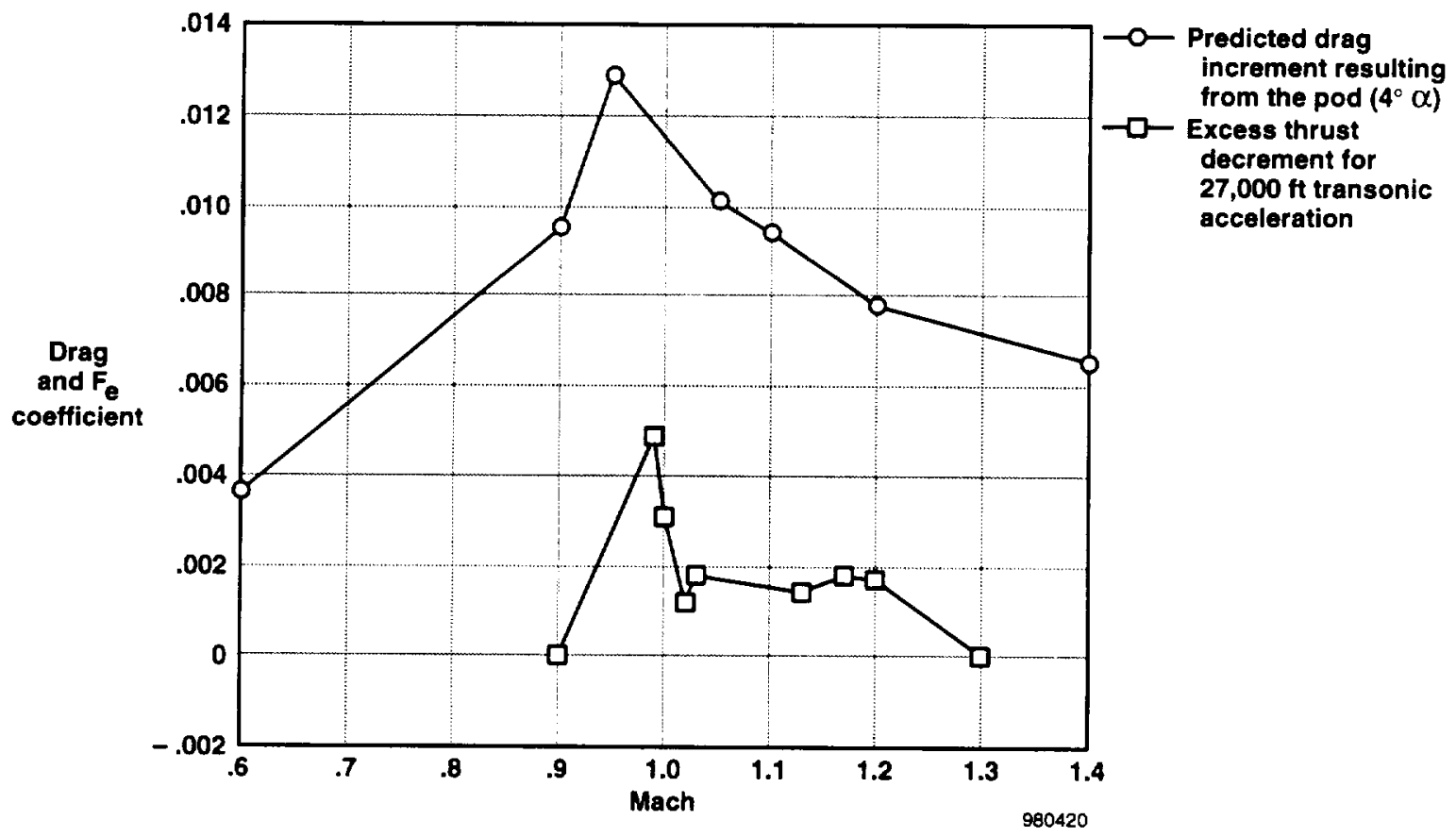

Figure 27. Comparison of the excess thrust increment for the transonic acceleration at an altitude of $27,000 \mathrm{ft}$ with the wind-tunnel predicted LASRE pod trimmed drag increment. 


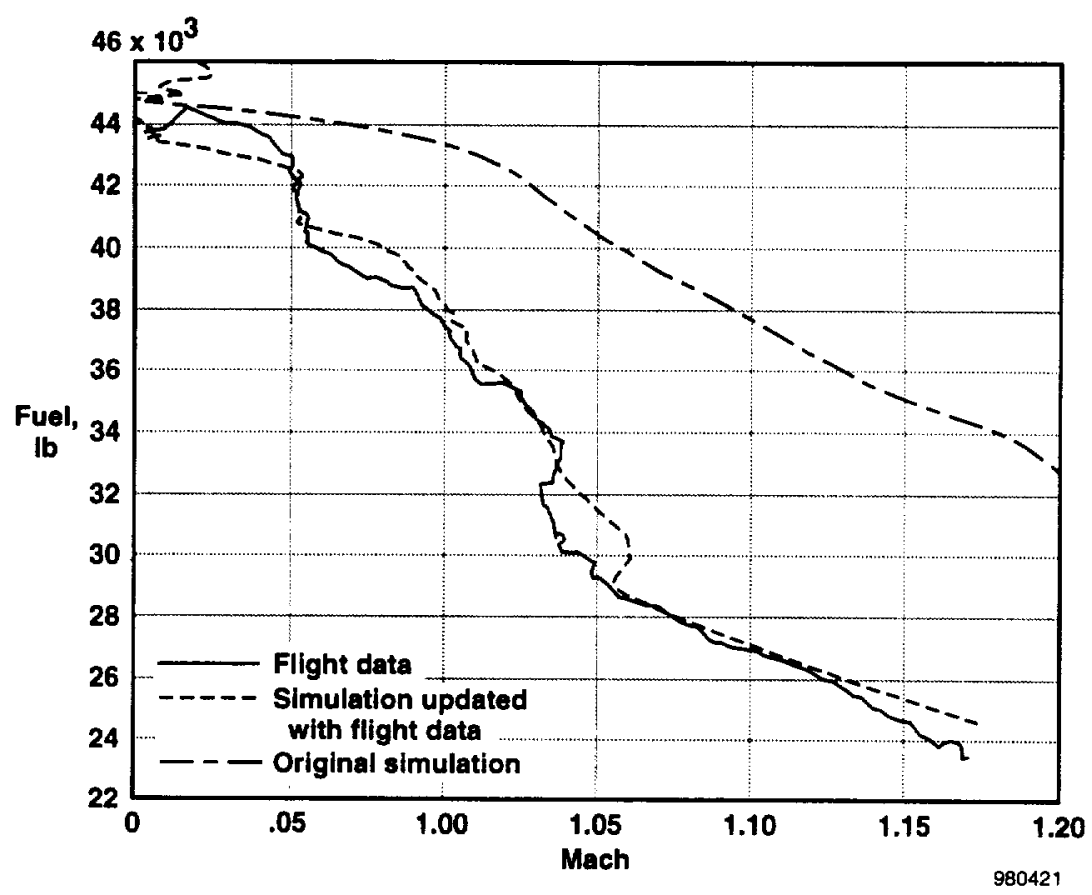

Figure 28. Flight and simulator fuel performance results for the transonic acceleration at an altitude of $27,000 \mathrm{ft}$ with the simulator excess thrust decremented according to flight results.

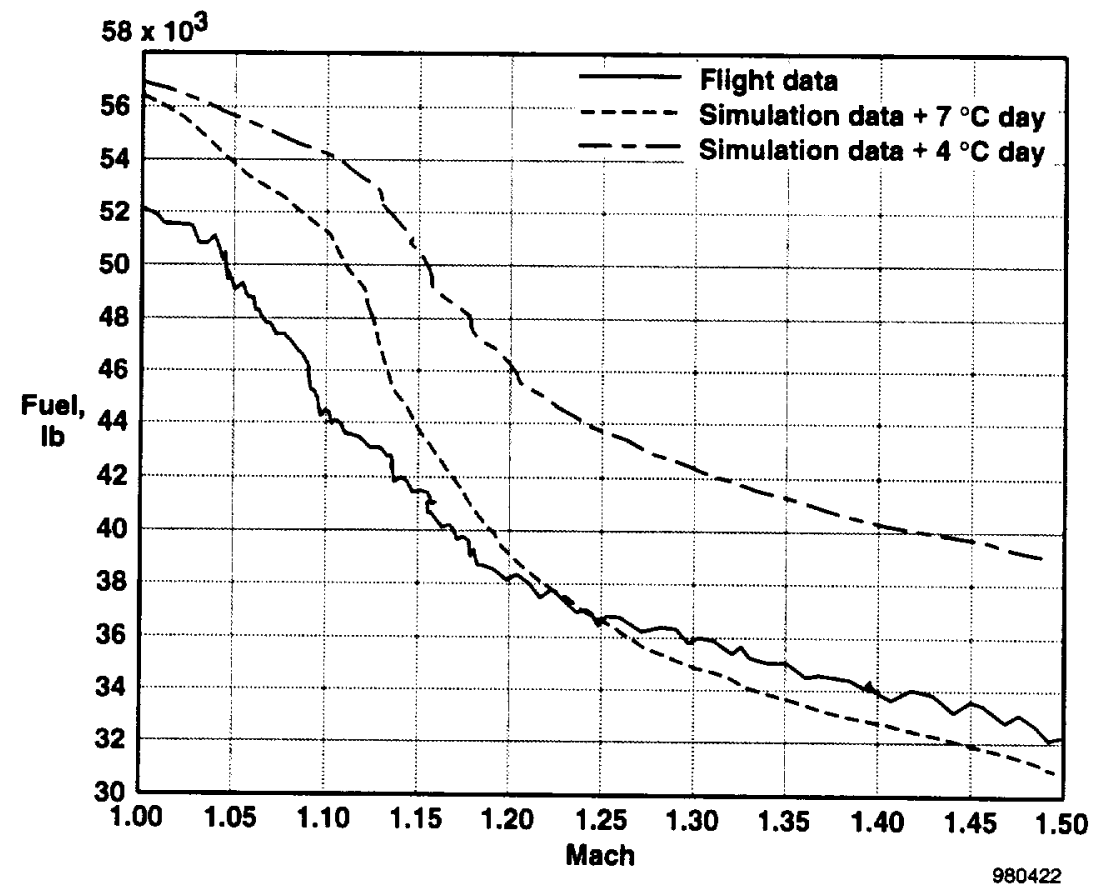

Figure 29. Fuel performance for a transonic acceleration at an altitude of $25,000 \mathrm{ft}$ and $455 \mathrm{KEAS}$ climb to Mach 1.5. 
included the excess thrust decrement obtained from the first flight (fig. 27). The simulator once again overpredicted transonic performance. Because drag is not a strong function of ambient temperature, it was concluded that the simulator does not correctly model J58 thrust changes as a function of ambient temperature. The shape of the flight curve agreed fairly well with the $+4{ }^{\circ} \mathrm{C}$ curve. After more simulation studies, it was concluded that the flight data for $\mathrm{a}+1^{\circ} \mathrm{C}$ day could be approximated very well with $\mathrm{a}+5^{\circ} \mathrm{C}$ day simulation.

After completion of the initial level-altitude transonic accelerations that were required for flutter clearance, a more efficient piloting technique was used to improve the transonic penetration. Instead of accelerating at a level altitude, the acceleration began at an altitude of $28,000 \mathrm{ft}$ and the pilot put the aircraft into a slight dive to help get through the transonic drag rise. The pilot leveled the aircraft at approximately Mach 1.07 and $25,000 \mathrm{ft}$, which was the minimum altitude limit for transonic Mach numbers. Results from two of these maneuvers flown on two different days are shown in figure 30. During the acceleration from Mach 1.0 to 1.3, the flight 5 maneuver required approximately $5000 \mathrm{lb}$ more fuel than the flight 3 maneuver. Two factors contributed to this poorer performance; slightly warmer temperature and the c.g. on flight 5 was approximately
1 percent farther forward than on flight 3. Postflight simulations showed that the forward c.g. would account for less than $400 \mathrm{lb}$ more fuel usage during the acceleration. This comparison further demonstrates that small changes in temperature have a significant effect on transonic performance for the LASRE configuration.

\section{Concluding Remarks}

Flight stability and control tests and performance tests have been successfully completed for the LASRE configuration at speeds up to Mach 1.8. Flight data have been compared with preflight wind tunnel predictions.

Flight parameter estimation analyses of the LASRE configuration showed good agreement with wind tunnel predictions of longitudinal stability, $C_{m_{\alpha}}$, and elevon control effectiveness, $\quad C_{m_{\delta e}}$, for transonic and supersonic Mach numbers. Below Mach 0.9, the elevon control effectiveness was less than predicted by up to 20 percent. However, flight data shows that the baseline SR-71 aerodynamic model also overpredicted elevon effectiveness by about the same amount. LASRE configuration transonic directional stability, $C_{n_{\beta}}$, was less than predicted with the worst case being 30-percent less. As a result of the pod, the aircraft dihedral effect,

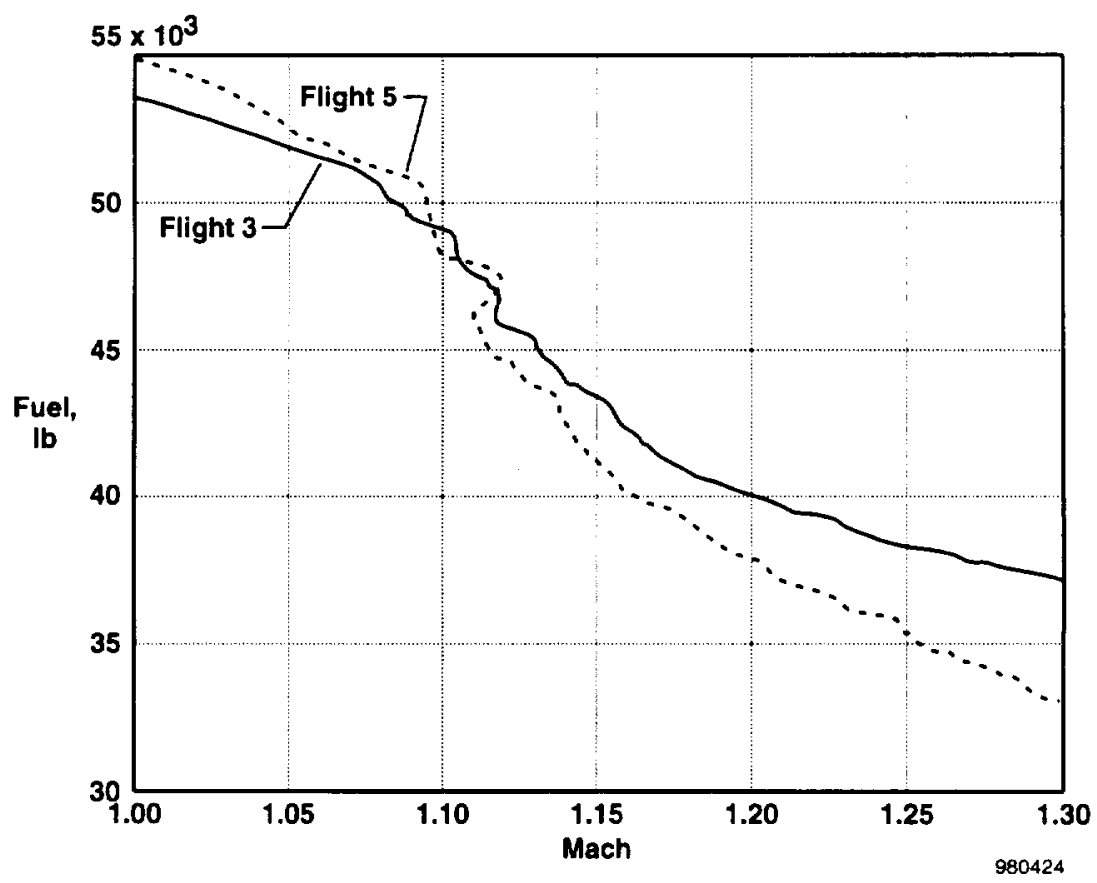

(a) Available fuel.

Figure 30. Transonic accelerations from two flight days with different ambient temperatures. 


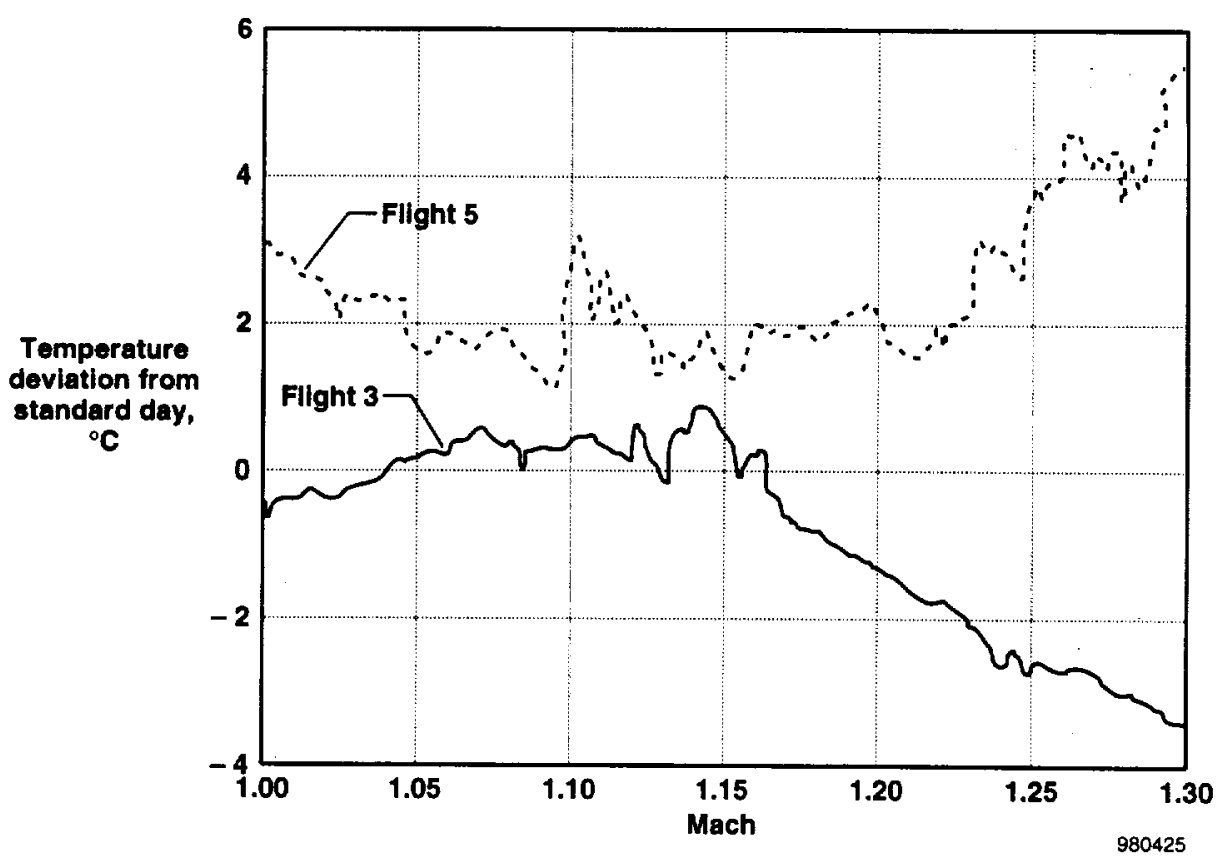

(b) Temperature deviation from standard day.

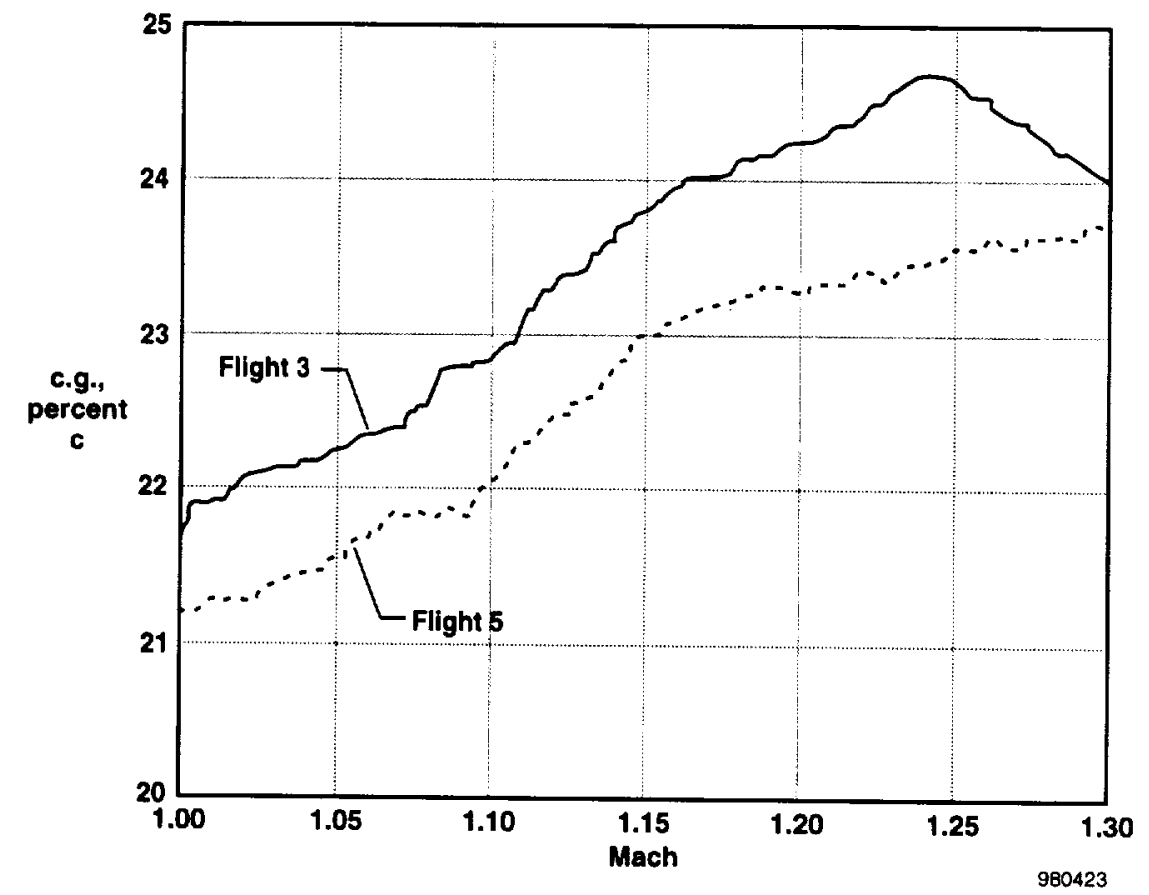

(c) Center of gravity.

Figure 30. Concluded. 
$C_{l_{\beta}}$, was also less than predicted by up to 50 percent. Rudder effectiveness, $C_{n_{\delta}}$, was as much as 23 -percent less than predicted, whereas aileron effectiveness, $C_{l_{\delta a}}$, agreed well with predictions. In general, simulator values for subsonic values of the baseline SR-71 aerodynamic derivatives were not as good as the supersonic values. Although LASRE stability and control effectiveness were lower than predicted in many cases, the aircraft flying qualities were never significantly worse than predicted.

Wind tunnel data had predicted that the pod would cause a significant amount of noseup and nosedown pitching moment as the aircraft accelerated through the transonic Mach numbers. The flight data showed significantly more noseup pitching moment increment resulting from the pod than had been predicted, with the peak at Mach 0.95. The predicted nosedown pitching moment increment at Mach 1.2 never materialized.

Piloted simulations using the flight-corrected stability and control derivatives were done for potential emergency situations and aerospike rocket firings. In all cases, these simulations showed acceptable handling qualities and aircraft responses that were within acceptable load factor and angle of sideslip limits.

The performance analysis of the LASRE configuration is still ongoing. Flight data clearly showed that the ability of the LASRE configuration to obtain required project test points was highly dependent on ambient temperature because of the effect of temperature on J58 engine performance. The colder the temperature at altitude, the better the aircraft was able to accelerate to supersonic flight. It was also determined that the piloted simulator did not correctly model ambient temperature effects on J58 engine thrust. The simulator consistently overpredicted transonic performance for the baseline SR-71 and the LASRE configuration. An excess thrust analysis was done to quantify the performance difference between flight data and simulation results. On a LASRE flight with ambient temperature approximately $9{ }^{\circ} \mathrm{C}$ above standard temperature, the excess thrust difference between flight and simulation was 25 percent of the expected pod drag increase at Mach 1.02 and greater. The difficult question to answer is how much of the measured excess thrust difference is a result of wind tunnel misprediction of the LASRE drag increment and how much is caused by the J58 thrust modeling error of the simulation. The flight results can only conclusively state that the wind tunnel prediction of the LASRE drag increment was within 25 percent for Mach numbers greater than 1.02 .

\section{$\underline{\text { References }}$}

${ }^{1}$ Martinez, A., Aerodynamic Nozzle Study, vol. 1, Rocketdyne Final Report R-6582, North American Aviation, Inc., Los Angeles, California, July 15, 1966.

${ }^{2}$ Martinez, A., Aerodynamic Nozzle Study, Slipstream Studies, vol. III, Rocketdyne Interim Report R-6273, North American Aviation, Inc., Los Angeles, California, July 31, 1965.

${ }^{3}$ Moes, Timothy R., Brent R. Cobleigh, Timothy R. Conners, Timothy H. Cox, Stephen C. Smith, and Norm Shirakata, Wind-Tunnel Development of an SR-7I Aerospike Rocket Flight Test Configuration, AIAA 962409, NASA TM-4749, June 1996.

${ }^{4}$ Corda, Stephen, David P. Lux, Edward T. Schneider, and Robert R. Meyer, Jr., "Blackbird puts LASRE to the Test," Aerospace America, vol. 36, no. 2, pp. 24-29, Feb. 1998.

${ }^{5}$ Maine, Richard E. and Kenneth W. Iliff, Application of Parameter Estimation to Aircraft Stability and Control - The Output-Error Approach, NASA RP-1168, June 1986.

${ }^{6}$ Murray, James E. and Richard E. Maine, pEst Version 2.1 User's Manual, NASA TM-88280, Sept. 1987.

${ }^{7}$ Meyer, J. E., J. R. McMaster, and R. L. Moody, Handling Qualities of the SR-71, Lockheed Aircraft Corporation, Report no., SP-508, Burbank, California, Oct. 29, 1964.

${ }^{8}$ U.S. Standard Atmosphere, National Aeronautics and Space Administration, United States Air Force, United States Weather Bureau, ICAO Standard Atmosphere to 20 Kilometers, 1962. 
Pubtic reporting burden for this coliection of intormation is estimated to average 1 hour per response, including the time tor reviewing instructions, searching existing data sources, gathering and maintaining the data needed, and completing and reviewing the collection of information. Send comments regarding this burden estimate or any other aspect of this collection of intormation. including sugestions tor reducing this burden, to Washington Headquarters Services. Directorate for information Operations and Reports, 1215 Jetferson Davis Highway, Suite 1204 , Arlington. VA 22202-4302, and to the Otfice of Management and Budget, Paperwork Reduction Project (0704-0188), Washington, DC 20503.

\begin{tabular}{|l|l|l|}
\hline 1. AGENCY USE ONLY (Leave blank) & $\begin{array}{c}\text { 2. REPORT DATE } \\
\text { August } 1998\end{array}$ & $\begin{array}{c}\text { 3. REPORT TYPE AND DATES COVERED } \\
\text { Technical Memorandum }\end{array}$ \\
\hline
\end{tabular}

\begin{tabular}{l|l} 
4. TILE AND SUBTTLE & 5. FUNDING NUMBERS
\end{tabular}

Flight Stability and Control and Performance Results from the Linear Aerospike SR-71 Experiment (LASRE)

6. AUTHOR(S)

WU 244-33-02-00-23-00-T15

Timothy R. Moes, Brent R. Cobleigh, Timothy H. Cox, Timothy R.

Conners, Kenneth W. Iliff, and Bruce G. Powers

7. PERFORMING ORGANIZATION NAME(S) AND ADDRESS(ES)

NASA Dryden Flight Research Center

P.O. Box 273

Edwards, California 93523-0273

H-2276

9. SPONSORINGMONITOAING AGENCY NAME(S) AND ADDRESS(ES)

10. SPONSORINGMONTTORING

AGENCY REPORT NUMBER

National Aeronautics and Space Administration

Washington, DC 20546-0001

NASA/TM-1998-206565

\section{SUPPLEMENTARY NOTES}

Presented at the AIAA Atmospheric Flight Mechanics Conference, August 10-12, 1998, Boston, MA. Timothy Moes, Brent Cobleigh, Timothy Cox, Timothy Conners, and Kenneth Iliff, NASA Dryden Flight Research Center, Edwards, CA; and Bruce Powers, Analytical Services and Materials, Inc., Edwards, CA.

\begin{tabular}{|l|l|} 
12a. DISTRIBUTIONAVAILABILTTY STATEMENT & 12b. DISTRIBUTION CODE
\end{tabular}

Unclassified-Unlimited

Subject Category 08

13. ABSTRACT (Maximum 200 words)

The Linear Aerospike SR-71 Experiment (LASRE) is presently being conducted to test a 20-percent-scale version of the Linear Aerospike rocket engine. This rocket engine has been chosen to power the X-33 Single Stage to Orbit Technology Demonstrator Vehicle. The rocket engine was integrated into a lifting body configuration and mounted to the upper surface of an SR-71 aircraft. This paper presents stability and control results and performance results from the envelope expansion flight tests of the LASRE configuration up to Mach 1.8 and compares the results with wind tunnel predictions. Longitudinal stability and elevator control effectiveness were well-predicted from wind tunnel tests. Zero-lift pitching moment was mispredicted transonically. Directional stability, dihedral stability, and rudder effectiveness were overpredicted. The SR-71 handling qualities were never significantly impacted as a result of the missed predictions. Performance results confirmed the large amount of wind-tunnel-predicted transonic drag for the LASRE configuration. This drag increase made the performance of the vehicle so poor that acceleration through transonic Mach numbers could not be achieved on a hot day without depleting the available fuel.

14. SUBJECT TERMS

Aerospike rocket, Flight test, LASRE, SR-71, Stability and control

\begin{tabular}{|l|l|}
\hline 17. SECURITY CLASSIFICATION & 18. SECUATTY CLASSIFICATION \\
OF REPORT & OF THIS PAGE \\
Unclassified & Unclassified \\
\hline
\end{tabular}

19. SECURITY CLASSIFICATION
OF ABSTRACT
Unclassified

9. SECURTYY CLASSIFICATION

Unclassified
15. NUMBER OF PAGES 33

16. PRICE CODE $\mathrm{AO} 3$

20. LIMTTATION OF ABSTRACT

Unlimited 